\title{
The leaf-level emission factor of volatile isoprenoids: caveats, model algorithms, response shapes and scaling
}

\author{
Ü. Niinemets ${ }^{1}$, R. K. Monson ${ }^{2}$, A. Arneth ${ }^{3}$, P. Ciccioli $^{4}$, J. Kesselmeier ${ }^{5}$, U. Kuhn ${ }^{6}$, S. M. Noe ${ }^{1}$, J. Peñuelas ${ }^{7}$, and \\ M. Staudt ${ }^{8}$ \\ ${ }^{1}$ Institute of Agricultural and Environmental Sciences, Estonian University of Life Sciences, Kreutzwaldi 1, \\ Tartu, 51014, Estonia \\ ${ }^{2}$ Department of Ecology and Evolutionary Biology and Cooperative Institute for Research in Environmental Sciences, \\ University of Colorado, Boulder, CO 80309-0334, USA \\ ${ }^{3}$ Division of Physical Geography and Ecosystem Analysis, Lund University, Sölvegatan 12, Lund, 22362, Sweden \\ ${ }^{4}$ Istituto di Metodologie Chimiche del CNR, Area della Ricerca di Roma 1, Monterotondo Scalo, 00016, Italy \\ ${ }^{5}$ Max Planck Institute for Chemistry, Biogeochemistry Department, Joh.-J.-Becher Weg 27, Mainz, 55128, Germany \\ ${ }^{6}$ Federal Research Station Agroscope Reckenholz-Taenikon, ART, Zuerich, Switzerland \\ ${ }^{7}$ Global Ecology Unit CSIC-CEAB-CREAF, Facultat de Ciències, Universitat Autònoma de Barcelona, \\ Bellaterra, 08193, Spain \\ ${ }^{8}$ Centre d'Ecologie Fonctionnelle et Evolutive (CEFE-CNRS), 1919, Route de Mende, Montpellier cedex 5, 34293, France
}

Received: 9 February 2010 - Published in Biogeosciences Discuss.: 17 February 2010

Revised: 25 May 2010 - Accepted: 25 May 2010 - Published: 1 June 2010

\begin{abstract}
In models of plant volatile isoprenoid emissions, the instantaneous compound emission rate typically scales with the plant's emission potential under specified environmental conditions, also called as the emission factor, $E_{\mathrm{S}}$. In the most widely employed plant isoprenoid emission models, the algorithms developed by Guenther and colleagues (1991, 1993), instantaneous variation of the steady-state emission rate is described as the product of $E_{\mathrm{S}}$ and light and temperature response functions. When these models are employed in the atmospheric chemistry modeling community, speciesspecific $E_{\mathrm{S}}$ values and parameter values defining the instantaneous response curves are often taken as initially defined. In the current review, we argue that $E_{\mathrm{S}}$ as a characteristic used in the models importantly depends on our understanding of which environmental factors affect isoprenoid emissions, and consequently need standardization during experimental $E_{\mathrm{S}}$ determinations. In particular, there is now increasing consensus that in addition to variations in light and temperature,
\end{abstract} $\begin{aligned} & \text { Correspondence to: } \text { Ü. Niinemets } \\ & \text { (ylo.niinemets@emu.ee) }\end{aligned}$

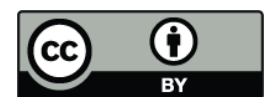

alterations in atmospheric and/or within-leaf $\mathrm{CO}_{2}$ concentrations may need to be included in the emission models. Furthermore, we demonstrate that for less volatile isoprenoids, mono- and sesquiterpenes, the emissions are often jointly controlled by the compound synthesis and volatility. Because of these combined biochemical and physico-chemical drivers, specification of $E_{\mathrm{S}}$ as a constant value is incapable of describing instantaneous emissions within the sole assumptions of fluctuating light and temperature as used in the standard algorithms. The definition of $E_{\mathrm{S}}$ also varies depending on the degree of aggregation of $E_{\mathrm{S}}$ values in different parameterization schemes (leaf- vs. canopy- or region-scale, species vs. plant functional type levels) and various aggregated $E_{\mathrm{S}}$ schemes are not compatible for different integration models. The summarized information collectively emphasizes the need to update model algorithms by including missing environmental and physico-chemical controls, and always to define $E_{\mathrm{S}}$ within the proper context of model structure and spatial and temporal resolution.

Published by Copernicus Publications on behalf of the European Geosciences Union. 


\section{Introduction}

Plant-released volatile organic compounds (BVOC) are major determinants of atmospheric oxidative capacity and play important roles in formation of secondary organic aerosols and cloud condensation nuclei with important implications for the Earth's climate (Engelhart et al., 2008; Kulmala et al., 2004; Mentel et al., 2009; Peñuelas and Staudt, 2010; Spracklen et al., 2008). Among BVOC, volatile isoprenoids, isoprene and methylbutenol (C5), monoterpenes (C10) and sesquiterpenes (C15), deserve special attention because of high reactivity in the atmosphere and their large contribution, often more than $90 \%$, to total plant emissions. Atmospheric chemistry and transport and chemistry-climate models require accurate estimation of the source strength of volatile isoprenoids with satisfactory spatial and temporal resolution. For biome to global-scale predictions of air chemistry and climate, BVOC emission estimates with a spatial resolution of $100-10000 \mathrm{~km}^{2}$, depending on the process studied, can be satisfactory, but for regional air quality assessments, the emission estimates need to be of very high temporal $(\sim 1 \mathrm{~h})$ and spatial $\left(1-50 \mathrm{~km}^{2}\right)$ resolution to appropriately account for the source variability (Eder et al., 1993; Fiore et al., 2003; Logan, 1989; Loughner et al., 2007). Such high resolution data are obtained using predictive models that require climatic forcing variables, information on plant leaf area, architecture of plant stands, species composition and isoprenoid emission potentials as input data and provide emission rates, typically in hourly resolution, as model output.

In these models, the key characteristic determining the emission capacity of vegetation is the emission potential $\left(E_{\mathrm{S}}\right)$, separately determined for different classes of volatile isoprenoids, isoprene, monoterpenes and sesquiterpenes. As originally defined (Guenther et al., 1991, 1993), $E_{\mathrm{S}}$ is the steady-state emission rate corresponding to a specified arbitrarily defined set of environmental drivers. In the initial form of the models, leaf temperature (commonly fixed at $T_{\mathrm{L}}=30^{\circ} \mathrm{C}$ ) and light intensity (commonly fixed at $Q=1000 \mu \mathrm{mol} \mathrm{m}-2 \mathrm{~s}^{-1}$ ) were specified in definition of $E_{\mathrm{S}}$. Such a definition allowed for convenient simulation of volatile isoprenoid fluxes as the product of $E_{\mathrm{S}}$ and the normalized light and temperature functions, so called Guenther et al. algorithms (Guenther et al., 1991, 1993). A similar logic, defining the emission capacity and modifying this by environmental drivers was used in all upcoming emission models, even if including more detailed process-based descriptions of various biochemical steps and resulting environmental dependencies (Grote et al., 2006, 2010; Martin et al., 2000; Niinemets et al., 1999, 2002c; Zimmer et al., 2000).

At the time of its initial definition, $E_{\mathrm{S}}$ was defined at leaflevel as a species-specific average emission rate (Guenther et al., 1991, 1993). Once estimated, $E_{\mathrm{S}}$ values were often not modified in subsequent modeling exercises and the variation associated with any $E_{\mathrm{S}}$ determination was not considered with only very few exceptions (e.g., Guenther et al., 1994; Hanna et al., 2005). The shapes of light and temperature response functions (Guenther et al., 1991, 1993), were also often taken as originally defined. Up to present, the majority of atmospheric modeling exercises continue to be established on the premise of early definitions of $E_{\mathrm{S}}$ and response function shapes. However, over recent years it has become increasingly evident that apart from light and temperature, additional short- and medium-term drivers play an important role in modifying the emission rates (Arneth et al., 2007; Heald et al., 2009; Possell et al., 2005). In some recent efforts, modelers have grappled with ways to include some of these additional factors in their simulations (Arneth et al., 2007; Heald et al., 2009; Possell et al., 2005), while others have retained the simpler structure of the original models. As a result, the definitions of $E_{\mathrm{S}}$ have become variable among the models.

In particular, $\mathrm{CO}_{2}$ concentration response functions have been developed (Arneth et al., 2007; Possell et al., 2005; Wilkinson et al., 2009), and it has been suggested that $\mathrm{CO}_{2}$ concentrations also need standardization in defining $E_{\mathrm{S}}$ (Wilkinson et al., 2009). In addition, it has been demonstrated that the standardized emission rates as well as the shape of the temperature response curve can vary depending on the rate of temperature change (e.g., fast vs. slow temperature response curves; Singsaas et al., 1999; Singsaas and Sharkey, 2000). Furthermore, for less volatile mono- and sesquiterpenes, it has been shown that the steady-state assumption underlying $E_{\mathrm{S}}$ and environmental response curves is often not satisfied due to simultaneous controls of emissions by the rate of synthesis and volatility (Grote and $\mathrm{Ni}$ inemets, 2008; Niinemets and Reichstein, 2002; Noe et al., 2006, 2010; Schurgers et al., 2009a). This evidence collectively suggests that $E_{\mathrm{S}}$ as a modeling concept depends on the understanding of the biological, environmental and physico-chemical factors limiting isoprenoid emission and, thus, varies in dependence on the model structure.

Of course, every model is incomplete in its representation of the true biochemical and physico-chemical processes, and $E_{\mathrm{S}}$ is differently defined depending on the assumptions carried in each model. This recognition should compel us to continually assess missing processes and their importance to the uncertainties contained in model predictions, as well as lead us in identifying the strategies for model improvement. It is within this spirit that we have undertaken the current analysis as a means to evaluate the current state-of-affairs of isoprenoid emission models and definitions of $E_{\mathrm{S}}$. In this synthesis, we will begin by reviewing the traditional "Guenther et al." algorithms that have been so widely used in the modeling of plant isoprenoid emissions. We will also attempt to define these algorithms within the context of our knowledge about biochemical processes, thus establishing a mechanistic justification for their use. We also review the way the species-specific leaf-level $E_{\mathrm{S}}$ values are aggregated in higher scale emission models, and analyze the potential aggregation 
errors during the scaling of emission estimates from the leafto landscape-scales.

We use the overall analysis to emphasize that $E_{\mathrm{S}}$ as a modeling concept (vs. the emission rate measured under specified conditions) should always correspond to the structure, timestep and spatial resolution of the model used, and to highlight the prime areas for future experimental work needed for model improvement and application in highly variable field environments. In this analysis, we focus on instantaneous environmental responses, and consider acclimation of isoprenoid emission to environmental conditions as much as this is needed to understand the variability in the shape of environmental response curves and development of novel models (induced emissions). For acclimation, developmental and stress responses in $E_{\mathrm{S}}$ we refer to the accompanying paper (Niinemets et al., 2010).

\section{Models and definitions of $E_{S}$}

The definition of $E_{\mathrm{S}}$, the average emission rate under arbitrarily chosen standard conditions, largely depends on an understanding of the rapid emission controls and on the form of the specific emission model that is used. In the past, it has been considered safe to fix only light intensity and leaf temperature to derive $E_{\mathrm{S}}$ values for isoprene, a compound that is rapidly synthesized from a small carbon pool in chloroplasts. Moreover, it was considered sufficient to fix only temperature for monoterpenes emitted from a large pool in specialized storage tissues such as resin ducts and resin blisters in conifers (Guenther et al., 1991, 1993; Tingey et al., 1980). Later, it was observed that in several species lacking specialized storage tissues, monoterpene emissions depend on light availability in a manner similar to isoprene (Loreto et al., 1996c; Staudt and Seufert, 1995). It was further found that in species with large monoterpene reservoirs in storage tissues, light-dependent monoterpene emissions can also occur (e.g., Staudt et al., 1997).

Discovery of the light-dependent terpene emissions in both the non-storing and storing species caused us to reassess the definition of $E_{\mathrm{S}}$ for terpenes, and made clear that light intensity, in addition to temperature, must be controlled in determining monoterpene $E_{\mathrm{S}}$. To complicate matters even further, it was discovered that species lacking specialized storage tissues can exhibit light-dependent and lightindependent emissions, which can potentially interfere with each other (Kahl et al., 1999; Loreto et al., 1996a; Niinemets and Reichstein, 2002; Schuh et al., 1997). Thus, we were forced to develop mixed models or dynamic models for prediction of $E_{\mathrm{S}}$, especially for the emission of isoprenoids with higher molecular mass (Niinemets and Reichstein, 2002; Schuh et al., 1997).

Apart from light and temperature, isoprene emissions also vary in response to changes in $\mathrm{CO}_{2}$ concentration (Jones and Rasmussen, 1975; Loreto and Sharkey, 1990;
Mgalobilishvili et al., 1978; Monson and Fall, 1989). This physiological evidence has been neglected so far, and only recently, the importance of standardization of $\mathrm{CO}_{2}$ concentration inside the leaf for determination of $E_{\mathrm{S}}$ values has been recognized (Wilkinson et al., 2009).

The above discussion emphasizes that the definition of $E_{\mathrm{S}}$ depends on what environmental factors are considered as operative in altering the emission rate and thus needing standardization during the emission measurements. The definition of $E_{\mathrm{S}}$ is also different when the emissions come from a large pool of preformed compounds, or are immediately synthesized, or when they come simultaneously from both large existing pools and from de novo synthesis. Thus, the choice of the emission model used can crucially alter $E_{\mathrm{S}}$ estimations. In the following sections, various model approaches are summarized and model-specific sources of variation in emission rates are analyzed.

\subsection{Modeling standardized responses of volatile isoprenoids to key environmental factors in steady-state conditions}

Since the early 1990's, two prominent models, the so-called "Guenther et al. algorithms", have been used to simulate the responses of isoprene emissions to incident quantum flux density ( $Q$, light intensity) and leaf temperature $\left(T_{\mathrm{L}}\right)$ and the release of monoterpenes from storage tissues in dependence on temperature (Guenther, 1999; Guenther et al., 1991, 1993, $1995,1996 \mathrm{c})$. In the case of isoprene, the emission algorithm was constructed on the premise that the emissions are driven by the combined coupling of isoprenoid biosynthesis to photosynthetic processes and the temperature-dependence of enzyme activity, while the monoterpene release model was based on monoterpene vaporization and diffusion out of the storage tissues, i.e., on physical processes (see Guenther, 1999; Guenther et al., 1991, 1993, 1995, 1996c). Later, the isoprene emission algorithm was also employed to simulate methylbutenol (Harley et al., 1998; Schade et al., 2000) and light-dependent monoterpene emissions in species lacking specialized monoterpene storage tissues (Bertin et al., 1997; Ciccioli et al., 1997b; Dindorf et al., 2006; Kesselmeier et al., 1997; Kuhn et al., 2002; Steinbrecher et al., 1997). Additionally, $\mathrm{CO}_{2}$ response functions have recently been added to the Guenther et al. algorithms (Wilkinson et al., 2009), as well as to emission models that seek to link isoprenoid production directly to photosynthetic metabolism (Arneth et al., 2007; Schurgers et al., 2009a).

According to the Guenther et al. type of models, the volatile isoprenoid emission rate, $E$, is a product of the standardized emission rate, $E_{\mathrm{S}}$, and non-dimensional light, $f(Q)$, leaf temperature, $f\left(T_{\mathrm{L}}\right)$, and $\mathrm{CO}_{2}, f\left(C_{\mathrm{i}}\right)$, functions:

$E=E_{\mathrm{S}} f(Q) f\left(T_{\mathrm{L}}\right) f\left(C_{\mathrm{i}}\right)$.

The functions $f(Q), f\left(T_{\mathrm{L}}\right)$ and $f\left(C_{\mathrm{i}}\right)$ are normalized to 1.0 at standardized conditions used for $E_{\mathrm{S}}$ determination. 


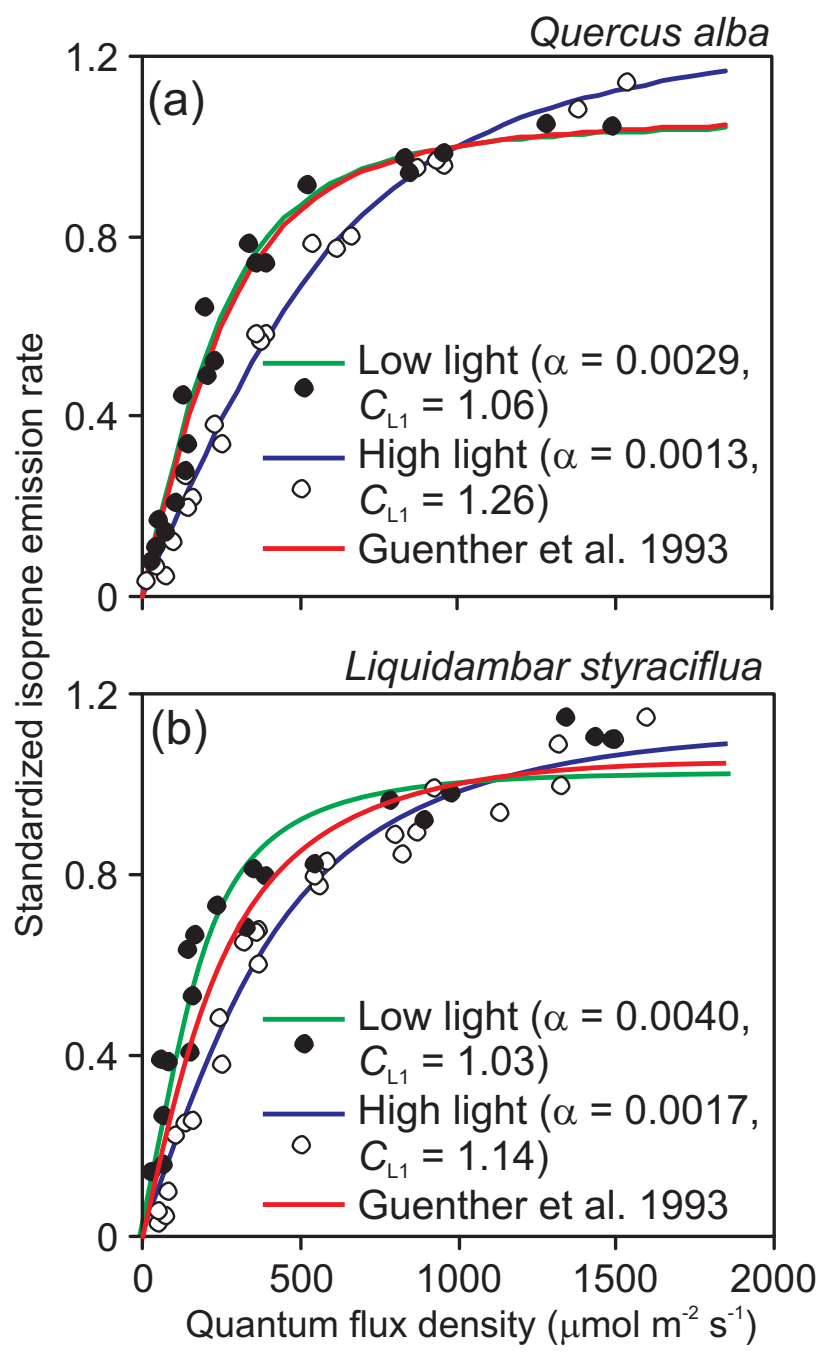

Fig. 1. The rate of isoprene emission in relation to incident quantum flux density (light intensity, $Q$ ) in temperate broad-leaved deciduous species Quercus alba (a) (data modified from Harley et al., 1997) and Liquidambar styraciflua (b) (data modified from Harley et al., 1996) studied in leaves from the lower and upper canopy. The emission rate was standardized with respect to the rate measured at $Q$ of $1000 \mu \mathrm{mol} \mathrm{m}^{-2} \mathrm{~s}^{-1}$ that is the typical light intensity at which the isoprenoid emission potential, $E_{\mathrm{S}}$, is defined (Guenther et al., 1993). The light response function (Eq. 2) was fitted to the data and the model parameters, $\alpha$, the apparent quantum yield, and $C_{\mathrm{L} 1}$, the scaling coefficient, are shown for the different responses. In addition, the original light-response function reported by Guenther et al. (1993) is shown in both panels (red lines).

For monoterpene emissions from storage compartments, $f(Q)=f\left(C_{\mathrm{i}}\right)=1$ in all cases.

\subsubsection{The light dependence $(f(Q)$ function)}

The dependence of isoprenoid emissions on incident quantum flux density $(Q)$ was originally described by a model similar to that used to simulate the net $\mathrm{CO}_{2}$ assimilation rate and its dependence on incident quantum flux density (Guenther et al., 1993); the so-called Smith's function (Smith, 1937; Tenhunen et al., 1976). This response function represents a classic rectangular hyperbola, with the emission rate approaching an asymptote as $Q$ approaches infinity:

$f(Q)=\frac{C_{\mathrm{L} 1} \alpha Q}{\sqrt{1+\alpha^{2} Q^{2}}}$,

where $\alpha$ is the apparent quantum yield of isoprenoid emission and $C_{\mathrm{L} 1}$ is the scaling constant to force the function to 1.0 at the standardized value of $Q$ (commonly taken as $1000 \mathrm{\mu mol} \mathrm{m}^{-2} \mathrm{~s}^{-1}$ ).

The metabolic basis for the $f(Q)$ function is not well understood. It is known that the 2-C-methyl-D-erythritol 4phosphate (MEP) pathway that leads to the synthesis of both isoprene and monoterpenes occurs in the chloroplasts, and is dependent on ATP and NADPH produced in the lightdependent reactions of photosynthesis (e.g., Lichtenthaler et al., 1997; Schwender et al., 1997). Additionally, the rate of production of glyceraldehyde 3-phosphate (G3P), a primary product of photosynthesis, and a main substrate of isoprene and monoterpene biosynthesis, is dependent on light intensity in rectangular hyperbolic fashion (Magel et al., 2006; Rasulov et al., 2009). Thus, there is good reason to believe that the rectangular hyperbolic shape of the $f(Q)$ function truly reflects a shape similar to that of the photosynthetic light response function.

In the initial model parameterization, values of $\alpha=0.0027 \mathrm{~mol} \mathrm{~mol}^{-1}$ and $C_{\mathrm{L} 1}=1.066$ were used for isoprene based on measurements in four species (Guenther, 1997; Guenther et al., 1993), and these values have been used in unmodified form in the majority of subsequent modeling studies that have employed the Guenther et al. (1991, 1993) algorithms. However, there is evidence of significant variation in the shape of the light response curve, in particular, among leaves from different canopy positions in a given species (Fig. 1a, b; Lerdau and Throop, 2000). Acclimation to low light conditions increases the apparent quantum yield for an incident light, $\alpha$, implying that the light function saturates at lower light intensities. Enhanced $\alpha$ in leaves from lower canopy likely reflects more efficient light harvesting in these leaves, compatible with greater foliage chlorophyll contents in low light (Niinemets, 2007 for a review).

Furthermore, there is a strong variation in $\alpha$ values among species (Fig. 1a, b; Funk et al., 2006; Lerdau and Throop, 2000). For instance, Funk et al (2006) obtained the best-fit average $\alpha$ value of 0.0015 for Eucalyptus saligna. Using the value of $\alpha$ of 0.0027 to simulate the emissions in this species would overestimate isoprene emission at all light intensities, especially under lower light. For example, the overestimation is $34 \%$ at a moderate light intensity of $500 \mu \mathrm{mol} \mathrm{m}^{-2} \mathrm{~s}^{-1}$ and it increases to $65 \%$ at $Q=200 \mu \mathrm{mol} \mathrm{m}^{-2} \mathrm{~s}^{-1}$, emphasizing the significance of using appropriate $\alpha$ values. In 
addition, analysis of light dependencies of methylbutenol (Harley et al., 1998; Schade et al., 2000) and light-dependent monoterpene emissions (Schuh et al., 1997; Staudt et al., 2003) also simulated by the same algorithm demonstrates that the shapes of the response curves for these volatile isoprenoids can be different from the response shape determined for isoprene (Sect. 2.2.2). Taken together, this evidence strongly suggests that using constant parameters of the light response function, $\alpha$ and $C_{\mathrm{L} 1}$, in large-scale simulation analyses can result in significant bias. In BVOC emission models, more effort should be devoted to gaining adequate parameterizations for the light response functions. Although quantitative information regarding the within-canopy variation in $\alpha$ is scarce (Harley et al., 1996, 1997), variations in $\alpha$ have been occasionally included in emission models, varying $\alpha$ values with cumulative leaf area index from canopy top to bottom (Guenther et al., 1999).

\subsubsection{The temperature dependence ( $f\left(T_{L}\right)$ function) for de-novo synthesized isoprenoids}

In the Guenther et al. $(1991,1993)$ algorithms, an Arrhenius type response was used for the temperature function, $f\left(T_{\mathrm{L}}\right)$, of isoprene emission. This function describes a curve with an optimum at $T_{\mathrm{m}}$ :

$f\left(T_{\mathrm{L}}\right)=\frac{\exp \left[\frac{C_{\mathrm{T} 1}\left(T_{\mathrm{L}}-T_{\mathrm{S}}\right)}{R T_{\mathrm{S}} T_{\mathrm{L}}}\right]}{1+\exp \left[\frac{C_{\mathrm{T} 2}\left(T_{\mathrm{L}}-T_{\mathrm{m}}\right)}{R T_{\mathrm{S}} T_{\mathrm{L}}}\right]}$,

where $C_{\mathrm{T} 1}$ and $C_{\mathrm{T} 2}$ are the parameters $\left(\mathrm{J} \mathrm{mol}^{-1}\right)$ characterizing the activation and deactivation energy of the emission, $R$ is the gas constant $\left(8.314 \mathrm{~J} \mathrm{~mol}^{-1} \mathrm{~K}^{-1}\right), T_{\mathrm{L}}$ is the leaf absolute temperature and $T_{\mathrm{S}}$ is the standard temperature (typically $303.16 \mathrm{~K}$ ) at which $f\left(T_{\mathrm{L}}\right)=1$. In initial temperature response function parameterization based on measurements in Eucalyptus globulus (Guenther et al., 1991), the values used were $C_{\mathrm{T} 1}=95100 \mathrm{~J} \mathrm{~mol}^{-1}, C_{\mathrm{T} 2}=231000 \mathrm{~J} \mathrm{~mol}^{-1}$, $T_{\mathrm{m}}=311.8 \mathrm{~K}$ and the temperature for standardization was taken as $301 \mathrm{~K}\left(27.8^{\circ} \mathrm{C}\right)$. Later, based on further measurements in three additional species, $T_{\mathrm{m}}$ was taken as $314 \mathrm{~K}$ and the temperature for standardization as $303.16 \mathrm{~K}\left(30^{\circ} \mathrm{C}\right)$ (Guenther et al., 1993). In addition, a non-dimensional empirical parameter $C_{\mathrm{T} 3}$ was included (Guenther, 1997):

$$
f\left(T_{\mathrm{L}}\right)=\frac{\exp \left[\frac{C_{\mathrm{T} 1}\left(T_{\mathrm{L}}-T_{\mathrm{S}}\right)}{R T_{\mathrm{S}} T_{\mathrm{L}}}\right]}{C_{\mathrm{T} 3}+\exp \left[\frac{C_{\mathrm{T} 2}\left(T_{\mathrm{L}}-T_{\mathrm{m}}\right)}{R T_{\mathrm{S}} T_{\mathrm{L}}}\right]} .
$$

$C_{\mathrm{T} 3}$ as originally introduced was taken as 0.961 (Guenther, 1997) to account for the circumstance that the original parameterization proposed in Guenther et al. (1993) did not yield $f\left(T_{\mathrm{L}}\right)=1.0$ at $30^{\circ} \mathrm{C}$. However, we note that combinations of $C_{\mathrm{T} 1}, C_{\mathrm{T} 2}$ and $T_{\mathrm{m}}$ can be found that satisfy the criterion $f\left(T_{\mathrm{S}}\right)=1.0$ without the need for an additional parameter.

In the atmospheric modeling community, the temperature response function is often used as originally developed,

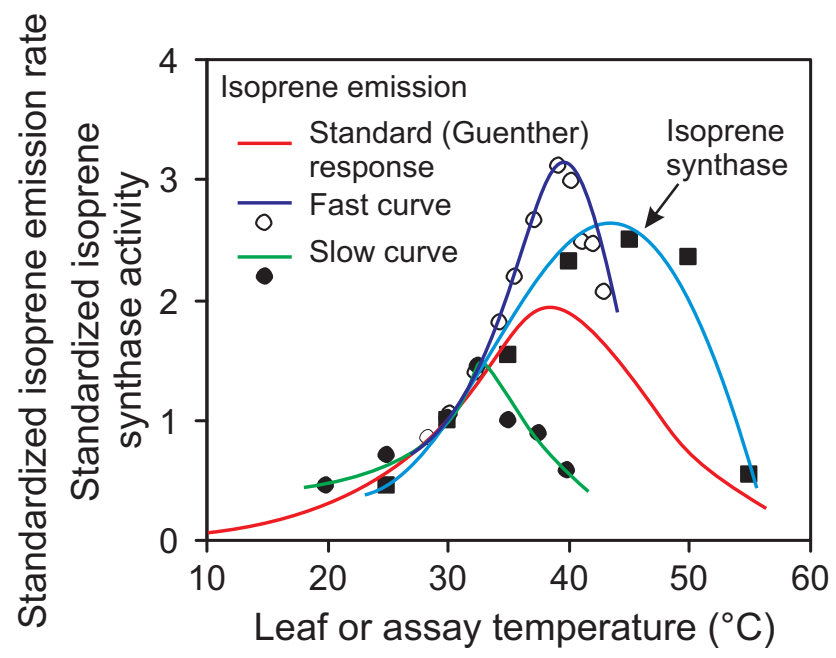

Fig. 2. Comparison of the temperature responses of isoprene synthase activity in Populus tremuloides (data from Monson et al., 1992), the "standard" isoprene emission curve by Guenther et al. (1993) model as re-parameterized (1997, Eq. 4) to yield a value of 1.0 at $30^{\circ} \mathrm{C}$, and the measurements of isoprene emission rate in Quercus rubra (data from Singsaas et al., 1999). These measurements were either conducted rapidly (4 min at each leaf temperature, fast curve) or slowly (30 min at each temperature, slow curve). In all cases, the data were standardized with respect to the measurements at $30^{\circ} \mathrm{C}$, yielding the temperature response function of isoprene emission.

even using the initial default parameterization of Guenther et al. (1991, 1993). This approach does not consider that the temperature response of isoprene emission is variable due to reasons not yet fully understood. The mechanistic basis for the temperature response function (Eq. 3) stems from enzyme kinetics, and Eq. (3) can be successfully parameterized to fit the in vitro temperature response of the isoprene synthase enzyme reaction (Lehning et al., 1999; Monson et al., 1992; Niinemets et al., 1999). Although the shapes of temperature responses of isoprene emission and isoprene synthase are similar, there are several important differences. In particular, isoprene synthase activity has a higher optimum temperature than isoprene emission rate and the "standard" isoprene emission curve by Guenther et al. (1993) lies at higher temperatures well below that for isoprene synthase (Fig. 2; Lehning et al., 1999; Monson et al., 1992), (s. also Niinemets et al., 1999 for the comparison of isoprene emission responses and synthase activity). In addition, the observed temperature dependence of isoprene emission differs depending on how measurements are made. When measurements are carried out fast, stabilizing the leaf for no more than 3-4 min at each temperature step, the temperature response curve of isoprene emission has a higher optimum than if measurements are conducted slowly, waiting until an apparent steady-state (30 min and more) is reached (Singsaas et al., 1999; Singsaas and Sharkey, 2000). 
The discrepancy from isoprene synthase enzyme kinetics and rapid time-dependent changes in temperature response curves (Niinemets et al., 2010 for longer-term acclimationtype changes) suggest that the temperature response of isoprene emission does not solely reflect enzyme kinetics, but also depicts changes in the immediate isoprene precursor, dimethylallyldiphosphate, DMADP, pool size (Niinemets et al., 1999). It is likely that with increasing temperature, isoprene synthase activity increases up to temperatures close to the point of irreversible thermal damage of chloroplasts (Fig. 2), while the DMADP pool size starts to decrease already under mild heat stress conditions that are inhibitory for photosynthetic $\mathrm{CO}_{2}$ uptake (production of glyceraldehyde 3-phosphate) and photosynthetic electron transport that are both needed for DMADP formation (Niinemets et al., 1999). Thus, the discrepancy between isoprene synthase and DMADP pool size becomes larger the longer the leaf stays at supraoptimal temperatures (Fig. 2 for the comparison of fast vs. slow temperature responses of isoprene emission and Singsaas et al., 1999; Singsaas and Sharkey, 2000).

Apart from the time-dependent effects, the temperature optimum can also be affected by physiological acclimation to growth temperature regime. Plants of the deciduous vine Mucuna pruriens have been shown to have lower temperature optima of isoprene emission when the growth temperature was decreased (Monson et al., 1992). The shape of the temperature response curve has also been shown to vary among the leaves from the top and bottom of tree canopies (Harley et al., 1996, 1997). This evidence collectively demonstrates that the shape of the isoprene temperature response function cannot be taken as constant, but it varies with the rate of change in leaf temperature during measurements and can also be modified upon acclimation to different environmental conditions (e.g., Mayrhofer et al., 2005; Wiberley et al., 2005). Modifications in the optimum temperature of isoprene emission in dependence on past temperature environment have been embedded in MEGAN (Guenther et al., 2006), but the quantitative data for parameterization of such relationships are very limited (Gray et al., 2003; Pétron et al., 2001; Sharkey et al., 1999).

How important is inclusion of species-specific and environmental variations in the shape of the temperature response curve in larger scale models? We conducted a simple sensitivity analysis by either reducing or increasing the optimum temperature by $5^{\circ} \mathrm{C}$ relative to the default parameterization (Guenther, 1997), while adjusting the other parameters such that the condition $f\left(T_{\mathrm{L}}\right)=1.0$ at $30^{\circ} \mathrm{C}$ was still satisfied. This sensitivity analysis demonstrated that if the "true" optimum temperature was $5^{\circ} \mathrm{C}$ less than the default value, the default parameterization underestimated $f\left(T_{\mathrm{L}}\right)$ by $7 \%$ at $25^{\circ} \mathrm{C}$ and overestimated by $95 \%$ at $40^{\circ} \mathrm{C}$. If the "true" optimum temperature was $5^{\circ} \mathrm{C}$ greater than the default value, the default parameterization overestimated $f\left(T_{\mathrm{L}}\right)$ by $2 \%$ at $25^{\circ} \mathrm{C}$ and underestimated by $34 \%$ at $40^{\circ} \mathrm{C}$. Thus, under certain environmental conditions, already moderate differences in optimum temperature can result in significant uncertainties that may need consideration in larger-scale predictions.

\subsubsection{The temperature dependence $\left(f\left(T_{L}\right)\right.$ function) for stored isoprenoids}

For species with monoterpenes stored in specialized leaf tissues, only physical evaporation and diffusion were originally suggested to control the emission rate and $f\left(T_{\mathrm{L}}\right)$ has been defined as (Guenther et al., 1993):

$f\left(T_{\mathrm{L}}\right)=\exp \left[\beta\left(T_{\mathrm{L}}-T_{\mathrm{S}}\right)\right]$,

where $\beta\left(\mathrm{K}^{-1}\right)$ is the temperature response coefficient characterizing the exponential increase of monoterpene vapor pressure and velocity of diffusion with temperature. In chemistry and biology, the temperature dependence of processes is often described according to the $Q_{10}$, the rate at temperature $T+10^{\circ} \mathrm{C}$ relative to the rate at temperature $T . Q_{10}$ values are then used to characterize the exponential increase in process rates as a function of temperature. $Q_{10}$ and $\beta$ are related as:

$Q_{10}=\exp (10 \beta)$,

In the original parameterization of the Guenther et al. (1993) algorithms, a value of $\beta=0.09 \mathrm{~K}^{-1}\left(Q_{10}=2.46\right)$ was taken as a median of 28 published estimates of $\beta$ for different plant species. The $\beta$ estimates in this compilation were mainly based on individual monoterpene species rather than on total monoterpene emissions (Guenther et al., 1993). Although $\beta$ varied more than 2.5 -fold $\left(0.057-0.144 \mathrm{~K}^{-1}\right)$ among these 28 estimates, in many past and contemporary simulation analyses, $\beta$ has been considered constant. Yet, in addition to the variability present in the $\beta$ values for individual monoterpenes, recent studies have highlighted important interspecific and seasonal variation in $\beta$ estimates for the sum of all emitted monoterpenes (Holzinger et al., 2006; Komenda and Koppmann, 2002; Llusià and Peñuelas, 2000; Ruuskanen et al., 2007; Tarvainen et al., 2005). Monoterpenes largely differ in volatility (saturated vapor pressure, partitioning between gas, liquid and lipid phases, Sect. 2.2) at given temperature (Table 1; Copolovici and Niinemets, 2005; Niinemets and Reichstein, 2002). Thus, these variations in $\beta$ values may reflect interspecific and seasonal differences in the composition of emitted monoterpenes (Sect. 2.4). Although quantitative measurements of sesquiterpene volatility are rare, sesquiterpenes are generally characterized by lower volatility than monoterpenes, and large differences in volatility occur among various sesquiterpenes as well (Bowles, 2003; Helmig et al., 2003; Paluch et al., 2009). Varying temperature response coefficients have been reported for monoand sesquiterpenes emitted by the same species (Ruuskanen et al., 2007), and different $\beta$ values have been observed for various mono- and sesquiterpenes (Llusià and Peñuelas, 2000; Tarvainen et al., 2005), supporting the association of $\beta$ values with compound volatility. 
Nevertheless, the $\beta$ values for any given mono- and sesquiterpene have been observed to vary during the season (Holzinger et al., 2006; Peñuelas and Llusià, 1999; Tarvainen et al., 2005). In Pinus sylvestris, $\beta$ for total monoterpenes varied between $0.076-0.18 \mathrm{~K}^{-1}$ over the season (data refer to two years of measurements), whereas the range of variation was occasionally more than 4 -fold for given monoterpene species, e.g., between $0.036-0.15 \mathrm{~K}^{-1}$ for $\alpha$-pinene (Tarvainen et al., 2005). Analogously, in Pinus ponderosa, the seasonal variation in $\beta$ for total monoterpenes was $0.11-$ $0.27 \mathrm{~K}^{-1}$ (Holzinger et al., 2006). These changes may reflect modifications in monoterpene diffusion conductance from the site of storage to the ambient atmosphere, but there are currently no experimental data about such modifications. An alternative explanation might be that in field studies, a limited temperature range is available for estimation of $\beta$ values (Holzinger et al., 2006). In seasonal climates, the range is shifted to lower temperatures in the beginning and end of the growing season and to higher temperatures in mid-season. As the rise of compound vapor pressure with temperature is not strictly exponential, but is typically fitted by a three-parameter Antoine equation (Copolovici and Niinemets, 2005; van Roon et al., 2002), $\beta$ for a given terpene will somewhat vary over different ranges of temperature. Thus, the variation in $\beta$ values recovered in seasonal field studies may reflect inadequacy of the single parameter temperature response function. As whole canopy measurements demonstrate, use of a constant $\beta$ value determined from summer measurements can result in ca. 50\% underestimation of whole-year monoterpene emissions (Holzinger et al., 2006).

A further shortcoming of current models of the temperature responses of monoterpene emission is that some species, which were traditionally considered to emit monoterpenes only from storage tissues, have now been shown to also emit monoterpenes that have been synthesized from recentlyassimilated $\mathrm{CO}_{2}$. These emissions are predicted to depend on temperature according to Eq. (3) and also depend on light according to Eq. (2). For instance, the temperate evergreen conifer Pinus sylvestris has been previously considered to be only a storage emitter (Janson, 1993). However, using stable carbon isotope $\left({ }^{13} \mathrm{C}\right)$ labeling to distinguish slow and fast turnover pools of monoterpenes, it was found that about $30 \%$ of emissions rely on de novo synthesis (fast turnover pools) in this species (Shao et al., 2001; see also the Sect. 2.3 for the light-dependent emissions of induced monoterpenes in other conifers). In such species with the emissions coming from both storage and de novo synthesis, modeling the temperature responses of emissions solely by Eq. (5) will be inadequate. $\beta$ will inevitably have to be defined as a mixed parameter depending on the temperature effects on enzyme activity, and physico-chemical properties of specific monoterpenes, including terpene-specific values of diffusion conductance. Simulation analyses demonstrate that temperature sensitivity of emissions relying on both de novo synthesis and storage
Table 1. Variation in physico-chemical characteristics of isoprene, non-oxygenated monoterpenes and monoterpene alcohols $\alpha$ terpineol and linalool at $25^{\circ} \mathrm{C}$.

\begin{tabular}{|c|c|c|c|}
\hline Compound $^{1}$ & $\begin{array}{l}\text { Henry's law } \\
\text { constant, } H_{\mathrm{xy}} \\
\text { mol/mol air } \\
\mathrm{mol} / \mathrm{mol} \text { water }\end{array}$ & $\begin{array}{l}\text { Octanol/water } \\
\text { partition } \\
\text { coefficient, } K_{\mathrm{OW}} \\
\frac{\mathrm{mol} / \mathrm{mol} \text { octanol }}{\mathrm{mol} / \mathrm{mol} \mathrm{water}}\end{array}$ & $\begin{array}{l}\text { Octanol/air } \\
\text { partition } \\
\text { coefficient, } K_{\mathrm{OA}} \\
\frac{\text { mol/mol octanol }}{\mathrm{mol} / \mathrm{mol} \text { air }}\end{array}$ \\
\hline Isoprene & 4266 & 29.09 & 0.00682 \\
\hline$\alpha$-Terpinene & 1914 & 866.5 & 0.453 \\
\hline$\alpha$-Pinene & 7435 & 3392 & 0.456 \\
\hline$\beta$-Pinene & 3772 & 4599 & 1.219 \\
\hline$\alpha$-Phellandrene & 3052 & 6601 & 2.163 \\
\hline$\beta$-Phellandrene & 3052 & 6684 & 2.190 \\
\hline S-(-)-Limonene & 1577 & 5537 & 3.511 \\
\hline $\mathrm{R}$-(+)-Limonene & 1563 & 5490 & 3.512 \\
\hline Terpinolene & 1457 & 5148 & 3.532 \\
\hline$\gamma$-Terpinene & 1433 & 5354 & 3.735 \\
\hline Linalool & 1.162 & 104.5 & 89.90 \\
\hline$\alpha$-Terpineol & 0.1238 & 105.6 & 853.1 \\
\hline
\end{tabular}

1 The compounds were ranked according to increasing values of $K_{\mathrm{OA}}$. Data for isoprene as revised in Niinemets and Reichstein (2003), data for other compounds from Copolovici and Niinemets $(2005,2007)$. The convention of units as in Staudinger and Roberts (2001).

can significantly differ from the emissions dominated by storage only, with $5{ }^{\circ} \mathrm{C}$ temperature change corresponding to 25-30\% difference in predicted emission rates (Schurgers et al., 2009a).

Finally, we note that the dependence of emissions on light suggests that values of $\beta$ may also differ among past studies due to lack of standardization for light during measurements of temperature response curves (e.g., measurements in darkness vs. measurements under light). With this new knowledge in hand, further experimental studies are called for to gain insight into causes of variations in $\beta$ values in emitters having terpene storage tissues.

\subsection{4 $\mathrm{CO}_{2}$ dependence $\left(f\left(C_{i}\right)\right.$ function)}

Apart from light and temperature, within leaf $\mathrm{CO}_{2}$ concentrations (intercellular $\mathrm{CO}_{2}$ concentration, $C_{\mathrm{i}}$ ) also vary during the day as the result of changes in stomatal conductance (a measure of stomatal openness), especially under low atmospheric humidities and in plants experiencing soil water deficit. These short-term (also called "instantaneous") influences of $C_{\mathrm{i}}$ are different from the effects of growth $\mathrm{CO}_{2}$ concentration on $E_{\mathrm{S}}$ (for reviews see Arneth et al., 2007; Niinemets et al., 2010; Young et al., 2009). The instantaneous influences of $C_{\mathrm{i}}$ on isoprenoid emissions likely reflect the partitioning of metabolites between the chloroplast and cytosol of plant cells (Rosenstiel et al., 2003), whereas the effect of growth $\mathrm{CO}_{2}$ concentration likely affects the expression of key enzymes (Loreto et al., 2007; Rosenstiel et al., 


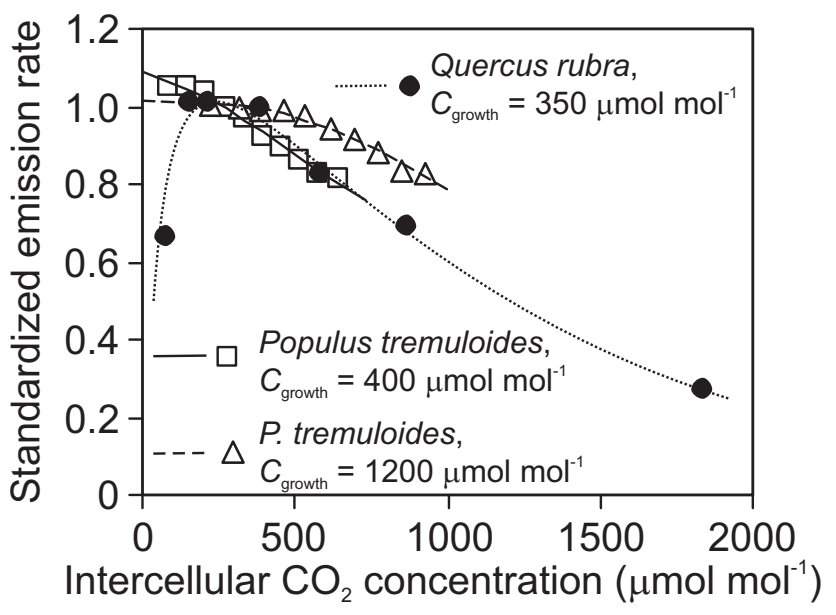

Fig. 3. Isoprene emission rate in relation to intercellular $\mathrm{CO}_{2}$ concentration $\left(C_{\mathrm{i}}\right)$ in Quercus rubra plants grown at an ambient $\mathrm{CO}_{2}$ concentration of $350 \mu \mathrm{mol} \mathrm{mol}^{-1}$ (data from Loreto and Sharkey, 1990) and in Populus tremuloides plants grown at ambient $\mathrm{CO}_{2}$ concentrations of 400 and $1200 \mu \mathrm{mol} \mathrm{mol}^{-1}$ (data from Wilkinson et al., 2009). Data for P. tremuloides were fitted by Eq. (7), while an empirical non-linear relationship with a maximum was used to fit the data for $Q$. rubra.

2004). The $\mathrm{CO}_{2}$-dependence function that is used to calculate $E$ in Eq. (1), refers to the instantaneous influence of $C_{\mathrm{i}}$.

Observations used to support parameterization of $f\left(C_{\mathrm{i}}\right)$ have demonstrated that isoprene emission rates decrease with increasing $\mathrm{CO}_{2}$ concentration above the current ambient $\mathrm{CO}_{2}$ concentrations of ca. $385 \mu \mathrm{mol} \mathrm{mol}^{-1}$, while the emissions increase at sub-ambient $\mathrm{CO}_{2}$ concentrations (Fig. 3; Loreto and Sharkey, 1990; Monson and Fall, 1989; Monson et al., 1991; Rasulov et al., 2009; Sharkey et al., 1991; Wilkinson et al., 2009). Fewer studies have further demonstrated that after the initial increase of isoprene emissions at lower $\mathrm{CO}_{2}$, the emissions level off and decrease again at $C_{\mathrm{i}}$ values below $100-150 \mathrm{mmol} \mathrm{mol}^{-1}$ (Fig. 3; Loreto and Sharkey, 1990; Rasulov et al., 2009).

Few studies have investigated the $\mathrm{CO}_{2}$ responses of higher molecular mass isoprenoid emissions. The immediate $\mathrm{CO}_{2}$ effects are expected to be small for terpene emissions from storage tissues, but effects similar to isoprene emissions are predicted for emissions of de novo synthesized terpenes. In agreement with this expectation, monoterpene emission rates were not different at 350 and $700 \mu \mathrm{mol} \mathrm{mol}^{-1}$ in terpenestoring species Rosmarinus officinalis (Peñuelas and Llusià, 1997). However, contrary to the predictions, monoterpene emission rates from the foliage of evergreen broad-leaved Quercus ilex that does not have specialized terpene storage tissues were also not significantly different between 350 and $1500 \mu \mathrm{mol} \mathrm{mol}^{-1}$ in Loreto et al. (1996b) and between 350 and $700 \mu \mathrm{mol} \mathrm{mol}^{-1}$ in Staudt et al. (2001a), although photosynthesis was stimulated by $1.4-1.8$-fold by higher $\mathrm{CO}_{2}$ in these studies. In contrast to this evidence, monoterpene emission rate was reduced at $1000 \mu \mathrm{mol} \mathrm{mol}^{-1}$ relative to $350 \mu \mathrm{mol} \mathrm{mol}^{-1}$ in the same species in the study of Rapparini et al. (2004). In addition, in a manner similar to that for isoprene, Loreto et al. (1996b) demonstrated a reduction of monoterpene emissions in $\mathrm{CO}_{2}$-free air in $Q$. ilex. Clearly more work on instantaneous $\mathrm{CO}_{2}$ responses of monoand especially sesquiterpene emissions is needed (Peñuelas and Staudt, 2010).

Definition of $f\left(C_{\mathrm{i}}\right)$ in Eq. (1) has been attempted based on biochemical knowledge of isoprene synthesis (Wilkinson et al., 2009). In particular, it has been assumed that isoprene production at different $\mathrm{CO}_{2}$ concentrations is determined by the partitioning of intermediates for DMADP synthesis between the cytosol and chloroplasts (Wilkinson et al., 2009). At low $C_{\mathrm{i}}, f\left(C_{\mathrm{i}}\right)$ was assumed to increase due to enhanced transport of triose phosphates from the cytosol into chloroplasts (Wilkinson et al., 2009), while at high $\mathrm{CO}_{2}$ concentration, $f\left(C_{\mathrm{i}}\right)$ was suggested to decrease due to increased use of phosphoenolpyruvate (PEP) in the cytosol by the enzyme PEP carboxylase, and thus decreased transport of PEP into the chloroplast for synthesis of isoprenoid compounds in the MEP pathway (Loreto et al., 2007; Monson et al., 2007; Rosenstiel et al., 2003). Thus, as $C_{\mathrm{i}}$ is increased due to increases in stomatal conductance or increases in ambient $\mathrm{CO}_{2}$ concentration, less substrate is made available for chloroplastic processes, such as DMADP synthesis, and the isoprene emission rate decreases. In contrast, when $C_{\mathrm{i}}$ is decreased, such as during moderate water stress, less PEP will be diverted away from DMADP synthesis, and isoprene biosynthesis rate will increase. Combining the two different processes and simplifying, Wilkinson et al. (2009) proposed the following empirical equation based on measurements in four tree species to describe the dependence of isoprene emissions on short-term variations in $C_{\mathrm{i}}$ :

$f\left(C_{\mathrm{i}}\right)=E_{\max }-\frac{E_{\max } C_{\mathrm{i}}^{h}}{C_{*}^{h}+C_{\mathrm{i}}^{h}}$,

where $E_{\max }$ is the isoprene emission rate normalized to a reference concentration, taken as $400 \mu \mathrm{mol} \mathrm{mol}^{-1}$ and $h$ and $C_{*}$ are empirical coefficients. This function describes data obtained over the $C_{\mathrm{i}}$ range of ca. $150-1000 \mu \mathrm{mol} \mathrm{mol}^{-1}$ reasonably well (Fig. 3). However, the mechanism proposed cannot explain the reduction of isoprene emissions below ca. $150 \mu \mathrm{mol} \mathrm{mol}^{-1}$ (Fig. 3). In addition, the shape of the $f\left(C_{\mathrm{i}}\right)$ function varies among plants adapted to different atmospheric $\mathrm{CO}_{2}$ concentrations (Fig. 3; Wilkinson et al., 2009), complicating the use of Eq. (7) for simulation of the $\mathrm{CO}_{2}$-response in plants in different $\mathrm{CO}_{2}$ atmospheres.

Alternative approaches, such as the control of isoprene (Rasulov et al., 2009) and monoterpene (Niinemets et al., 2002c) synthesis by energy supply from photosynthetic electron transport have been suggested to describe the full $\mathrm{CO}_{2}$ dependence of volatile isoprenoid emission, and have been semi-empirically included in predictive models (Arneth et 
al., 2007; Schurgers et al., 2009a). Such an approach can be promising as it allows description of both light and $\mathrm{CO}_{2}$ responses of isoprene by the same mechanism; although it has not yet been conclusively shown that the $\mathrm{CO}_{2}$ dependence of isoprene emission is caused by dynamics in photosynthetic electron transport. More experimental work is needed to determine the basis for the exact shape of the $\mathrm{CO}_{2}$ responses function, the biochemical basis for the effect of growth $\mathrm{CO}_{2}$ concentration on the shape of the response, and the interactions between $f\left(C_{\mathrm{i}}\right), f(Q)$ and $f\left(T_{\mathrm{L}}\right)$.

\subsection{Key differences between the emission algorithms of highly volatile isoprene and less volatile mono- and sesquiterpenes emitted in light-dependent manner}

As noted in Sect. 2.1, several species have specialized storage tissues such as resin ducts, oil glands, and glandular trichomes for terpene storage. In such species, large compound storage pools are generally in equilibrium with the compound concentration in the leaf gas-phase, and emissions are predicted by simplified models based on temperature effects on compound vaporization and diffusion out of storage pools (Eq. 5). After the detection of the light-dependence of monoterpene emissions in broad-leaved species lacking specialized storage tissues (Loreto et al., 1996c; Staudt and Seufert, 1995), and analogous findings for sesquiterpenes (Hansen and Seufert, 2003), the isoprene emission algorithm (Eqs. 1-3) has been applied to simulate light- and temperature-dependent emissions of these other compounds (e.g., Bertin et al., 1997; Ciccioli et al., 1997b; Dindorf et al., 2006; Kesselmeier et al., 1997; Kuhn et al., 2002; Pio et al., 2005). However, monoterpenes and sesquiterpenes have lower volatility than isoprene, and the crucial question is to what extent the use of the isoprene emission algorithm is justified.

\subsubsection{Non-specific storage of isoprenoids}

Volatility is a basic physico-chemical characteristic of any emitted organic compound. Volatility can be characterized by the gas/water partition coefficient - Henry's law constant, $H, \mathrm{~mol} \mathrm{~mol}^{-1} \mathrm{air} /\left(\mathrm{mol} \mathrm{mol}^{-1} \mathrm{H}_{2} \mathrm{O}\right)$ - that describes the partitioning of the compound to the gas phase, and octanol/water partition coefficient $-K_{\mathrm{OW}}$, mol mol ${ }^{-1}$ octanol $/\left(\mathrm{mol} \mathrm{mol}^{-1} \mathrm{H}_{2} \mathrm{O}\right)$ - that characterizes the partitioning of the compound to the lipid phase (Niinemets et al., 2004). The smaller the value of $H$, the more a compound tends to be stored (concentrated) in the leaf liquid phase, and the larger the value of $K_{\mathrm{OW}}$, the more a compound tends to be stored in the leaf lipid phase (Niinemets and Reichstein, $2002,2003)$. The ratio $K_{\mathrm{OW}}$ to non-dimensional form of Henry's law constant gives the octanol to air partition coefficient $K_{\mathrm{OA}}$ (Chen et al., 2003; Copolovici et al., 2005; Meylan and Howard, 2005). For isoprene and monoterpenes, the values of $K_{\mathrm{OW}}$ vary by more than two orders of magnitude, the values of $H$ by over four orders of magnitude, and the values of $K_{\mathrm{OA}}$ by over five orders of magnitude (Table 1 ). Typically, the values of $H$ and $K_{\mathrm{OW}}$ are low for oxygenated water-soluble compounds such as the monoterpene alcohols linalool and $\alpha$-terpineol, and the values of $H$ and $K_{\mathrm{OW}}$ are large for non-oxygenated monoterpenes (Table 1; Copolovici and Niinemets, 2007; Copolovici et al., 2005). In contrast, isoprene has a large $H$ and a low $K_{\mathrm{OW}}$, implying that this compound is preferably partitioned to the gas phase with minor storage capacity in the leaf liquid and lipid phases.

Depending on the specific physico-chemical characteristics, certain monoterpenes can be non-specifically stored within the leaves of species that lack dedicated monoterpene storage tissues (Loreto et al., 1996b; Staudt and Seufert, 1995). Those compounds with low $H$ (e.g., linalool, 1,8cineole) can be stored in the leaf liquid phase (Niinemets et al., 2002b; Noe et al., 2006). Compounds with high $K_{\text {OW }}$ such as non-oxygenated mono- and sesquiterpenes can be stored in the leaf lipid phase consisting of lipid bilayers in various membrane structures and other leaf hydrophobic regions (cuticle, lignified cell wall regions) (Niinemets and Reichstein, 2002; Noe et al., 2006, 2008). Such a non-specific storage of monoterpenes inside leaves can be important in modifying the time-dependent kinetics of emissions, implying that control over the emission rate is shared between monoterpene synthesis and volatility. While monoterpene synthesis in these species is believed to be rapidly modified by temperature and light, non-specific storage induces time-lags between compound synthesis and emission. The presence of a foliar pool of "old" monoterpenes synthesized previously is supported empirically by stable carbon isotope labeling experiments that switch between ${ }^{12} \mathrm{CO}_{2}$ and ${ }^{13} \mathrm{CO}_{2}$ and concomitantly monitor changes in the fractions of ${ }^{12} \mathrm{C}$ and ${ }^{13} \mathrm{C}$-labelled monoterpenes (Loreto et al., 1996a; Noe et al., 2006, 2010). All these experiments demonstrate important time-lags from hours to tens of hours between the start of ${ }^{13} \mathrm{C}$-labelling and attainment of a steady-state ${ }^{13} \mathrm{C}$-labelled monoterpene emission rate (Fig. 4). Although filling the immediate intermediate pools for monoterpene synthesis is also partly responsible for the lags in ${ }^{13} \mathrm{C}$-labelling (Grote et al., 2006, 2009; Noe et al., 2010), the turnover of intermediate pools is relatively fast and the overall ${ }^{13} \mathrm{C}$-labelling kinetics is determine by the pool of non-specifically stored monoterpenes (Noe et al., 2010).

The presence of non-specific storage also implies that emissions do not respond immediately to modifications in environmental variables (Fig. 4). For instance, due to non-specific storage, the increase of the emissions can be slower than predicted by a steady-state light-response function (Eq. 2), and the emissions may continue for hours into the dark period (Fig. 4; Niinemets et al., 2002a; Peñuelas et al., 2009), resulting in night emissions in species considered to be light-dependent emitters (Niinemets, 2008; Niinemets et al., 2002a). This type of pattern is in marked contrast with the isoprene emission model that predicts an instant response 

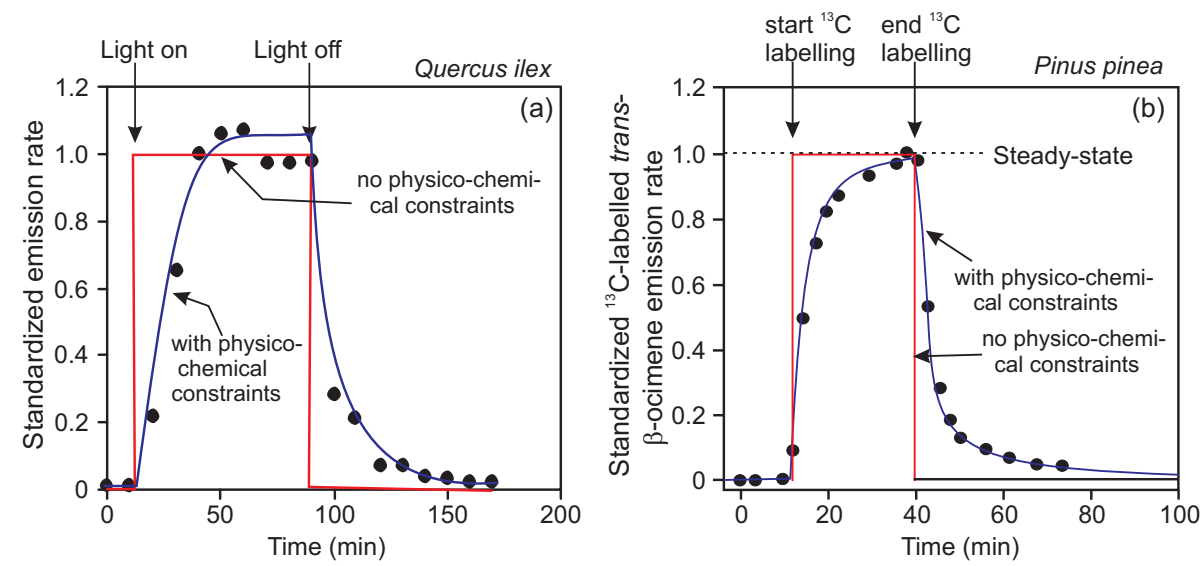

Fig. 4. Interaction of physiological and physico-chemical factors in determining the total light-dependent monoterpene emission rate in the Mediterranean evergreen sclerophyll Quercus ilex (a) (modified from Ciccioli et al., 1997b) and light-dependent emissions of monoterpene trans- $\beta$-ocimene in the Mediterranean conifer Pinus pinea (b) (modified from Noe et al., 2006) at a constant temperature of $30^{\circ} \mathrm{C}$. (a) depicts the transient of the emission rates after light-dark changes, while (b) depicts the emissions of ${ }^{13} \mathrm{C}$-labelled trans- $\beta$-ocimene following the switch from ${ }^{12} \mathrm{CO}_{2}$ to ${ }^{13} \mathrm{CO}_{2}$ in the gas-exchange chamber, and after a steady-state was reached in labeled trans- $\beta$-ocimene emissions, from ${ }^{13} \mathrm{CO}_{2}$ to ${ }^{12} \mathrm{CO}_{2}$. Given that the synthesis of monoterpenes relies on a small chloroplastic carbon pool, application of a simple steady-state model initially developed for isoprene (Guenther et al., 1993) suggests that monoterpene emission rate immediately tracks the altered light intensity (a) and that in all the emitted trans- $\beta$-ocimene molecules at least one carbon atom is labeled by ${ }^{13} \mathrm{C}$ (b, simulation without the storage pool). In reality, reaching the steady-state is time-consuming due to non-specific monoterpene storage within the leaf liquid and lipid phases (Niinemets and Reichstein, 2002; Noe et al., 2006). This leads to time-lags in reaching the maximum monoterpene emission rates and continued release of monoterpenes from darkened leaves (a), as well as to time-lags in trans- $\beta$-ocimene labeling with ${ }^{13} \mathrm{C}$ and de-labeling after swapping back to ${ }^{12} \mathrm{CO}_{2}$. The best fit to the data can be obtained with a model including two leaf monoterpene pools, the faster pool presumably located in the leaf liquid phase and the slower pool presumably located in the leaf lipid phase (Niinemets and Reichstein, 2002; Noe et al., 2006). For (a), the half-time for the faster pool was $0.078 \mathrm{~h}$, while the half-time was $2.05 \mathrm{~h}$ for the slower pool (Niinemets and Reichstein, 2002). For (b), the corresponding half-times obtained were $0.03 \mathrm{~h}$ for the faster, and $0.26 \mathrm{~h}$ for the slower pool (Noe et al., 2006).

of emissions to light (Eqs. 1-2). In addition, as different emitted monoterpenes have different volatilities (Table 1), the time-lags induced due to non-specific storage are different for different terpenes (Niinemets and Reichstein, 2002; Noe et al., 2006). This leads to time-dependent modifications in the fractional composition of emitted monoterpenes under non-steady state conditions (Niinemets and Reichstein, 2002).

Niinemets and Reichstein (2002) and Noe et al. (2006) have developed a dynamic model to consider the effects of non-specific storage on monoterpene emission kinetics. At least two pools, $S_{1}\left(\mathrm{nmol} \mathrm{m}^{-2}\right)$ and $S_{2}\left(\mathrm{nmol} \mathrm{m}^{-2}\right)$ with varying time-kinetics (time constant $k_{1}$ and $k_{2}, \mathrm{~s}^{-1}$ ) were needed to simulate monoterpene emission rate at time $t$ (Niinemets and Reichstein, 2002; Noe et al., 2006):

$E(t)=k_{1} S_{1}(t)+k_{2} S_{2}(t)$,

where the pool kinetics are given as:

$\frac{d S_{1}(t)}{d t}=\eta I-k_{1} S_{1}(t)$

$\frac{d S_{2}(t)}{d t}=(1-\eta) I-k_{2} S_{2}(t)$.

Analytical solution of the model is provided in Niinemets and Reichstein (2002). In these equations, $\eta$ is the fraction of monoterpenes going to pool $S_{1}$, and 1- $\eta$ is the fraction going to pool $S_{2}$. The rate of compound synthesis, $I$, can be simulated by the standard Guenther et al. (1993) model (Eq. 1), with corresponding instantaneous light- (Eq. 2), temperature(Eq. 3) and $\mathrm{CO}_{2}$ - (Eq. 7) response functions. The pool $S_{1}$ was presumed to exist in the leaf liquid phase and $S_{2}$ in the lipid phase. Depending on the monoterpene physico-chemical characteristics, the half-times of non-specific storage vary from minutes (pool $S_{1}$ ) to hours (pool $S_{2}$ ), indicating that non-specific storage effects need consideration in simulating monoterpene emissions in species lacking specialized storage. Overall, the non-specific storage model provides a good fit to the data (Fig. 4).

\subsubsection{Implications of non-specific storage on $E_{S}$ and the shape of the light and temperature response functions}

In addition to the above-mentioned factors driving variability in light (Sect. 2.1.1) and temperature (Sect. 2.1.2) responses of isoprene emission, non-specific partitioning of monoterpenes into internal leaf tissues can alter both the temperature and light-responses of monoterpene emission rate, and such effects are particularly significant for modeling the dynamics of monoterpene emissions. Studies on 
the light-dependence of monoterpene emissions in species lacking specialized storage tissues have demonstrated that the light response of emissions has a different shape than the rectangular hyperbola produced by the isoprene response function (Schuh et al., 1997; Staudt et al., 2003). In particular, the initial part of the monoterpene emission response to light is often sigmoidal (Fig. 5). To parameterize the sigmoidal rise of the emissions as light intensity increases, it has been suggested to modify the Guenther et al. algorithm (Eq. 2) as (Schuh et al., 1997):

$f(Q)=C_{\mathrm{L} 1 \mathrm{~m}}\left(\frac{\alpha_{\mathrm{m}} Q}{\sqrt{1+\alpha_{\mathrm{m}}^{2} Q^{2}}}\right)^{2}$,

where $C_{\mathrm{L} 1 \mathrm{~m}}$ and $\alpha$ are the modified light response function parameters. This function has been shown to fit lightdependent monoterpene emissions better than the original isoprene emission algorithm (Fig. 5a; Dindorf et al., 2006; Schuh et al., 1997; Staudt et al., 2003). However, the sigmoidal shape of the light-response of monoterpene emissions likely results from non-specific monoterpene storage (Fig. 5b). Reaching a steady-state emission rate at any given light intensity can be time-consuming, taking tens of minutes (see e.g., Fig. 4a). In leaves with empty non-specific storage pools, the emission rate is initially less than the synthesis rate. In typical measurements of light response curves, starting from low light with a gradual increase of light, nonspecific storage leads to apparent sigmoidal shape of the light response curve (Fig. 5b).

Although the sigmoidal light response curves can be parameterized with the modified equation (Eq. 11), the subsequent model would not be effective in describing time-lags between changes in light intensity and monoterpene emission rate that occur, for example, during the course of a day (Fig. 4). To parameterize such patterns, a dynamic model (Eq. 8) is needed. In fact, such time-lags can be successfully simulated by deploying a simplified lag factor in the models rather than applying sigmoidal light-response functions. Especially in large-scale simulations, where relatively crude time resolutions on the order of $1 \mathrm{~h}$ are used, and vegetation can be assumed to be close to a steady-state, use of sigmoidal shape is expected to introduce even a larger bias in the predicted emissions than use of the standard steady-state light response curve developed for isoprene (Eq. 2). Yet, in these models, the value of $E_{\mathrm{S}}$ estimated from rapid light-responses will be inadequate.

To further account for monoterpene release in darkness and better parameterize the temperature dependence of existing models (e.g., Fig. 4a), it has been suggested to combine the light-dependent emission model (emission rate $E_{\mathrm{L}}$ ) and the model developed for species with specialized storage tissues (emission rate $E_{\mathrm{S}}$ ) (Schuh et al., 1997):

$E=E_{\mathrm{L}}+E_{\mathrm{S}}$.

In this mixed algorithm used to simulate emissions in broadleaved deciduous tree species Fagus sylvatica and herb

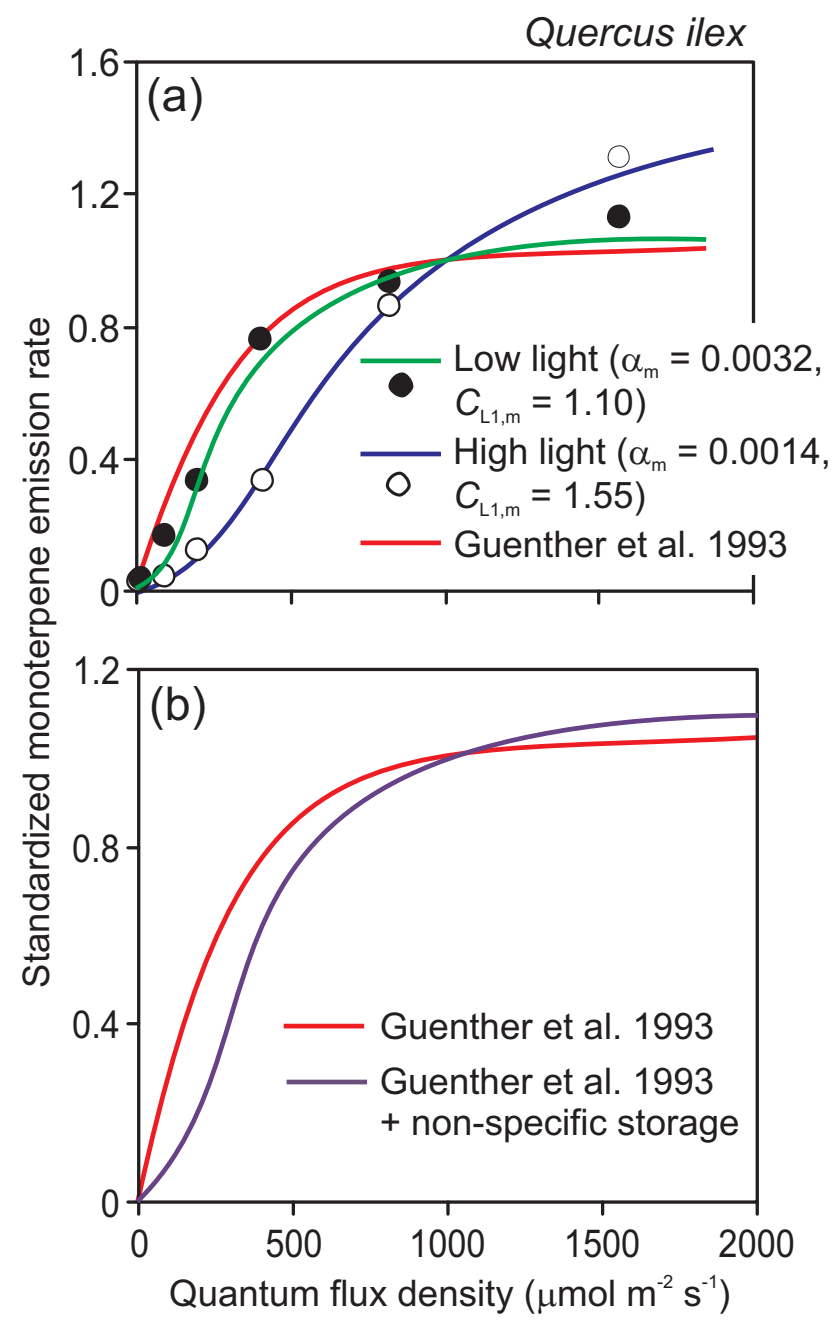

Fig. 5. Light-responses of monoterpene emission rate in the Mediterranean evergreen sclerophyll Quercus ilex grown under high and low light and comparison with Guenther et al. (1991) standard emission response (Eq. 2) (a) (data from Staudt et al., 2003), and (b) simulated responses of monoterpene emissions using a steadystate algorithm (Guenther et al., 1993) and a dynamic algorithm that considers the effect of non-specific storage on monoterpene emissions (Eq. 8; Niinemets and Reichstein, 2002). In the dynamic simulation, the synthesis rate of monoterpene emission at any light intensity was predicted by Guenther et al. (1993) algorithm, and the light level was increased by $50 \mu \mathrm{mol} \mathrm{m} \mathrm{m}^{-2} \mathrm{~s}^{-1}$ steps in every $2 \mathrm{~min}$. In (a), the data were fitted by modified light-response function suggested by Schuh et al. (1997; Eq. 11).

species Helianthus annuus, the emission rate from the nonspecific storage pool, $E_{\mathrm{S}}$, was exponentially dependent on temperature similar to Eq. (5), while $E_{\mathrm{L}}$ was described as dependent on light according to Eq. (11) and on temperature according to Eq. (3), and separate emission potentials were used for $E_{\mathrm{L}}$ and $E_{\mathrm{S}}$. Thus, under given conditions, this mixed model predicts that $E_{\mathrm{S}}$ makes a constant contribution to the total flux. However, the size of the non-specific storage 

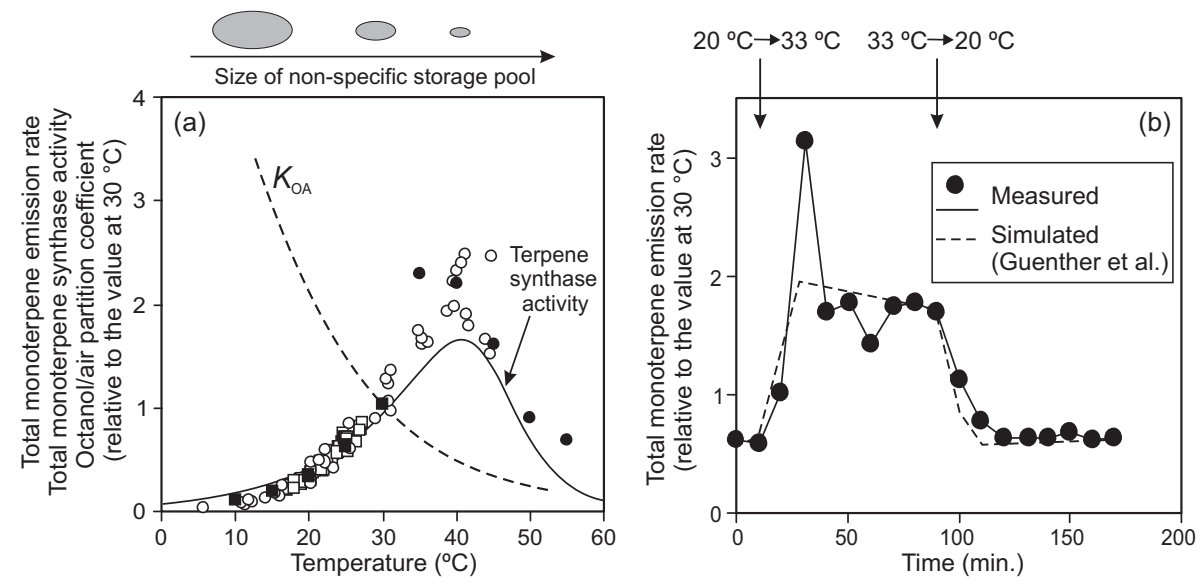

Fig. 6. Temperature effects on monoterpene emission rates from foliage of the broad-leaved evergreen Mediterranean sclerophyll Quercus ilex (symbols), on monoterpene synthase activity (solid line) and $\alpha$-pinene octanol-to-air partition coefficient $\left(K_{\mathrm{OA}}\right.$, dashed line) that characterizes the equilibrium size of non-specific monoterpene pool in the leaves (a), and time-dependent changes in monoterpene emissions from Q. ilex leaves after changes in temperature from $20^{\circ} \mathrm{C}$ to $33^{\circ} \mathrm{C}(\mathbf{b})$. In all cases, the data were normalized with respect to the value measured at $30^{\circ} \mathrm{C}$. The emission rate data in (a) are from Bertin and Staudt (1996; open squares), Staudt and Seufert (1995; filled squares), Staudt and Bertin (1998; open circles) and Loreto et al. (1998; filled circles) (Niinemets, 2004 for details on data compilation and fitting). The data in (b) are from Ciccioli et al. (1997a). All measurements were conducted at saturating light and cuvette $\mathrm{CO}_{2}$ concentrations of approximately $350 \mu \mathrm{mol} \mathrm{mol}^{-1}$. The measurements of monoterpene synthase activity are from Fischbach et al. (2000) and the $K_{\mathrm{OA}}$ estimations from Copolovici et al. (2005; Table 1). Physico-chemical factors likely explain differences between the rates of monoterpene emission and synthesis. As more monoterpenes can be non-specifically stored within the leaves at low temperatures, the emission rates are less than the synthase activity, while at higher temperatures, monoterpenes that have been accumulated at lower temperatures are released. Accordingly, leaves can transiently emit less or more monoterpenes than immediately synthesized. Emission of stored monoterpenes after switching to higher temperature likely explains the monoterpene emission burst in (b).

pool very much depends on the previous conditions, implying, for instance, that the emission rate in darkness decreases in time and that the response of the emission to a given increase or decrease in light level depends on how long the leaf has been under given conditions (Fig. 4a; Loreto et al., 1996a; Niinemets et al., 2002a). Such effects can only be simulated by a model based on dynamic pools (Eq. 8).

Although the mixed model (Eq. 12) predicts a stronger temperature response than the standard Guenther et al. (1991) model, it cannot predict bursts of emission following short-term increases in temperature such as occur during a single day (Fig. 6) and for hot days that follow cold days (e.g., Niinemets et al., 2002a). Such phenomena reflect the circumstance that when ambient temperatures are low, monoterpenes are non-specifically stored in leaf lipidand aqueous pools. Therefore, in hot days following such cool days, monoterpenes are released with a faster rate than predicted on the basis of temperature effects on the rate of monoterpene synthesis alone. Unlike the case for isoprene emission (Fig. 2), monoterpene emissions are characterized by large apparent $Q_{10}$ (emission rate at the temperature $T+10^{\circ} \mathrm{C}$ relative to the rate at $T$ ) values, even larger than those for monoterpene synthase activity (Fig. 6). Again, this large $Q_{10}$ value may reflect filling of the monoterpene pools under low temperature when compound volatility limits the emission rate, and transient emptying of these pools at higher temperature (Fig. 6). Parameterization and simulation of such hysteresis effects in the temperature response is possible only with a dynamic model such as Eq. (8).

From the evidence we have presented, it is clear that light-dependent monoterpene emissions reflect the contribution of both de novo monoterpene synthesis and emission of monoterpenes from storage. The value of $E_{\mathrm{S}}$ will approach the rate of monoterpene synthesis, $I$, as a steady state is approached. It is important to recognize the difference between the standardized emission rates when directly applying the Guenther et al. (1993) isoprene emission model and when using a dynamic model. In the dynamic model approach, the appropriate $E_{\mathrm{S}}$ needed is $E_{\mathrm{S}}=I$. For the steady-state model, even the best estimate of $E_{\mathrm{S}}$ yielding the smallest sum of error squares $\left(\min S_{\mathrm{S}}\right)$ between the predictions $\left(E_{\text {pred }}\right)$ simulated by Eq. (1) and observations ( $\left.E_{\text {obs }}\right)$ during the day (where $n$ is the number of measurements conducted during the day),

$\min S_{\mathrm{S}}=\sum_{i=1}^{i=n}\left(E_{\mathrm{pred}, i}-E_{\mathrm{obs}, i}\right)^{2}$,

will overestimate the emissions under some conditions, e.g., after induction of synthesis in the morning hours when light increases, and underestimate the emissions under other conditions, e.g., after reduction of synthesis rate in the afternoon 
when light decreases. Furthermore, the value of $E_{\mathrm{S}}$ that best fits the daily time-courses of emissions with a steadystate model does not necessarily coincide with the value of $E_{\mathrm{S}}$ measured under standardized conditions of $30^{\circ} \mathrm{C}$ and $1000 \mu \mathrm{mol} \mathrm{m}{ }^{-2} \mathrm{~s}^{-1}$. This conceptual difficulty further underscores that definition of $E_{\mathrm{S}}$ will differ depending on what model is used and even how the model is parameterized, e.g., measuring $E_{\mathrm{S}}$ values under standardized conditions or deriving $E_{\mathrm{S}}$ from Eq. (13) as the best fit value from field measured time-courses $\left(E_{\text {pred }}=f\left(E_{\mathrm{S}}\right)\right.$, Eq. 1$)$.

This evidence collectively demonstrates that the use of steady-state temperature- and light dependencies developed for isoprene emission (e.g., the Guenther et al. algorithms) in simulating the emissions of higher molecular mass compounds is likely to carry significant uncertainties and errors in the estimation of emissions from vegetation experiencing diurnal fluctuations in leaf temperature and light intensity. This is clearly an area that should receive high priority in future research.

\subsection{Towards the construction of models for induced emissions}

In the previous section, we focused on constitutive emissions present only in certain species. Yet, emissions of volatile compounds can be triggered by various biotic and abiotic stress factors in essentially all plant species (Arimura et al., 2009; Brilli et al., 2009; Niinemets, 2010; Wu and Baldwin, 2009). Furthermore, foliage sesquiterpene emissions are mostly associated with stress (Duhl et al., 2008; Hakola et al., 2006), and emissions of homoterpenes, $C_{11}$ compound DMNT (4,8-dimethylnona-1,3,7-triene) and $C_{16}$ compound TMTT (4,8,12-trimethyltrideca-1,3,7,11-tetraene) are exclusively associated with stress, in particular, with biotic stress (Arimura et al., 2009; Herde et al., 2008; Vuorinen et al., 2007; Wu and Baldwin, 2009). The stress-driven monoterpene emissions are often dominated by specific stress-marker compounds such as the oxygenated monoterpenes linalool and non-oxygenated ocimenes (Blande et al., 2007; Cardoza et al., 2002; Martin et al., 2003; Pinto et al., 2007; Staudt and Bertin, 1998; Staudt et al., 2003). In addition to these specific compounds, a blend of monoterpenes can often be elicited that resembles the emissions in constitutive emitters such as emissions of $\alpha$ - and $\beta$-pinene, limonene etc. (Brilli et al., 2009; Huber et al., 2005; Paré and Tumlinson, 1998; Paré and Tumlinson, 1999). To further complicate matters, such typical monoterpene emissions can be triggered in species emitting these compounds constitutively (Huber et al., 2005; Staudt and Lhoutellier, 2007). Clearly, stress-induced emissions cannot always be separated from the modulation of constitutive emissions by environment and physiology and also because the stressors are not always directly visible (e.g., small sap-sucking herbivores such as spider mites).

An important implication of induced emissions is that standardized emission rates $\left(E_{\mathrm{S}}\right)$ can vary widely depending on whether plants have been exposed to or are suffering from certain biotic or abiotic stresses. The presence of induced emissions can explain why species found to be nonemitters in some studies, are subsequently observed to be strong emitters in other studies. For example, temperate deciduous broad-leaved Betula spp. have been found to be low mono- and sesquiterpene emitters in some studies and during certain times of the year, with emission rates in standardized conditions only on the order of $0.1-0.4 \mu \mathrm{g} \mathrm{g}^{-1} \mathrm{~h}^{-1}$ (Hakola et al., 1998, 2001; König et al., 1995). In other studies and at other times of the year, they have been found to be moderately strong emitters, with $E_{\mathrm{S}}$ values on the order of 1.5$8 \mu \mathrm{g} \mathrm{g}^{-1} \mathrm{~h}^{-1}$ and the emissions dominated by the monoterpenes linalool and ocimenes, and by sesquiterpenes (Hakola et al., 1998, 2001; König et al., 1995; Owen et al., 2003; Steinbrecher et al., 1999). In analogous manner, a large variability, more than 80 -fold, is present in $E_{\mathrm{S}}$ values in the Mediterranean evergreen conifer Pinus pinea (Fig. 7). In this species, emissions during the wet and cool season are dominated by the monoterpene limonene (constitutive emissions), while the emissions in the hot dry season are dominated by the monoterpenes linalool and trans- $\beta$-ocimene (induced emissions) (Niinemets et al., 2002b; Staudt et al., 1997, 2000). Importantly, even in the constitutive emitters, the induced emissions can exceed constitutive emissions by several-fold (Fig. 7).

Currently, the variation in $E_{\mathrm{S}}$ values due to induced emissions cannot be considered in simulation models. There is encouraging evidence that stress dose versus induced emission relationships can be derived (Beauchamp et al., 2005; Karl et al., 2008; Niinemets, 2010), making it possible to include induced emissions in future models. Despite this evidence, there is currently limited information on the stress thresholds leading to elicitation of induced emissions and also on how the stress thresholds vary with species constitutive and induced tolerance to given environmental driver and biotic stress (Niinemets, 2010). Evidently, much more experimental work is needed for quantitative incorporation of induced emissions into large scale predictive models. Apart from quantifying the stress dose vs. emission response relationships, inclusion of induced emissions requires a capacity to predict large scale environmental and biotic disturbances such as insect outbreaks (Arneth and Niinemets, 2010).

The other important issue with induced emissions is that the induced monoterpenes (Brilli et al., 2009; Niinemets et al., 2002b; Ortega et al., 2007; Staudt et al., 1997), DMNT (Staudt and Lhoutellier, 2007), and sesquiterpenes (Hansen and Seufert, 2003; Staudt and Lhoutellier, 2007) are often emitted in light-dependent manner. For constitutive emitters, the presence of parallel induced emissions can greatly complicate efforts to characterize $E_{\mathrm{S}}$. For instance, in Pinus pinea, low-level constitutive emissions dominated by limonene are only dependent on temperature (Staudt et al., 1997, 2000) and can be simulated by Eq. (5). In contrast, the induced emissions dominated by linalool and 


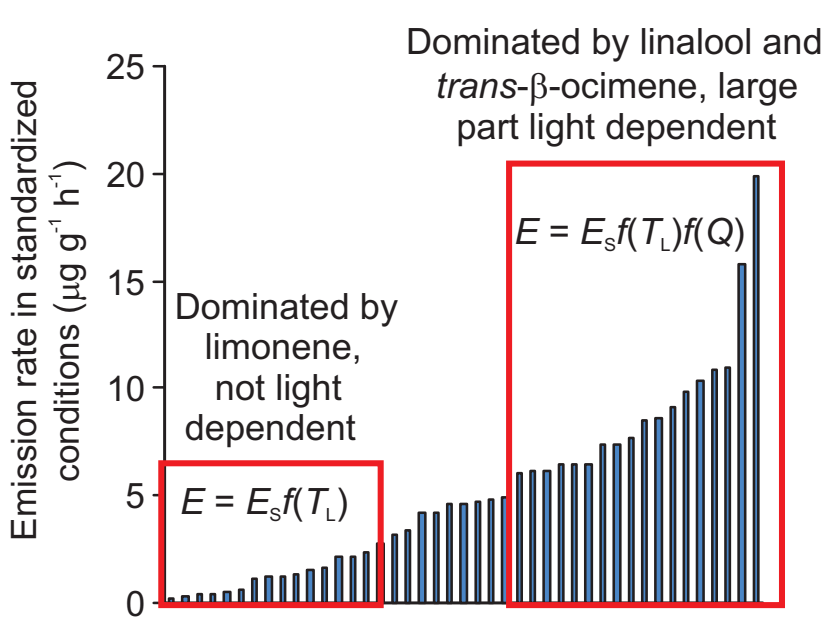

Fig. 7. Estimates of monoterpene emission rate under standardized conditions (leaf temperature, $T_{\mathrm{L}}=30^{\circ} \mathrm{C}$, incident quantum flux density, $Q=1000 \mu \mathrm{mol} \mathrm{m}^{-2} \mathrm{~s}^{-1}$ ), "the emission potential" ( $\left.E_{\mathrm{S}}\right)$ from the foliage of Mediterranean evergreen conifer Pinus pinea (data of Corchnoy et al., 1992; Kesselmeier et al., 1997; Owen et al., 1997, 1998, 2001, 2002; Owen and Hewitt, 2000; Pio et al., 1993; Sabillón and Cremades, 2001; Seufert et al., 1997; Staudt et al., 1997, 2000; Street et al., 1997; Winer et al., 1983). The estimates of $E_{\mathrm{S}}(n=43)$ were ranked from the smallest to the largest. In studies demonstrating low $E_{S}$, the emissions were typically dominated by the monoterpene limonene and were not light-dependent (constitutive emissions). In studies demonstrating large emissions, the emissions were typically dominated by the monoterpenes linalool and trans- $\beta$-ocimene that are considered as typical stress-induced monoterpenes. These emissions were both light- and temperature dependent (e.g., Niinemets et al., 2002b; Staudt et al., 1997). Thus, conceptually, the constitutive emissions can be predicted by Eq. (5), induced emissions by Eqs. (2) and (3), and total emissions by Eq. (12). However, due to non-specific storage of induced monoterpenes (Noe et al., 2006), a dynamic model is needed to describe these emissions (Eqs. 8-10).

trans- $\beta$-ocimene depend both on light and temperature (Niinemets et al., 2002b; Staudt et al., 1997) and are better simulated by Eqs. (2) and (3). Thus, the total emission rate (induced and constitutive) can be simulated using the mixed model (Eq. 12). In reality, this situation is rendered even more complex due to physico-chemical effects resulting from the non-specific storage of induced monoterpenes (Niinemets et al., 2002b; Noe et al., 2006), requiring the use of a dynamic model (Eqs. 8-10). In addition, "constitutive" emission rate in storage emitters can significantly increase after the events of herbivory exposing the storage contents to the ambient air (Loreto et al., 2000). Thus, in conifer species, where the emissions are typically assumed to be simulated by only one simple temperature-dependent equation (Eq. 5), parameterization of daily time-courses may necessitate the use of a complex array of models. Given the fundamentally different controls on constitutive and induced emissions, it is important to separately define the emission potentials for constitutive (standardized emission rate in the absence of induced emissions) and induced (standardized emission rate in the absence of constitutive emissions) emissions.

\subsection{Consideration of alterations in mono- and sesquiterpene compositions in models}

Terpene-emitting species release simultaneously many different compounds. This reflects the presence of several different terpene synthases in plant foliage as well as production of several terpenes by the same terpene synthases (Alonso and Croteau, 1993 for a review). For instance, monoterpene emitting species can release more than 20 different monoterpenes (Niinemets et al., 2002c for a review of monoterpenes released from the foliage of Quercus ilex). In isoprenoid emission and modeling studies, $E_{\mathrm{S}}$ for monoterpenes is generally taken as a sum of all monoterpenes emitted and $E_{\mathrm{S}}$ for sesquiterpenes as a sum of all sesquiterpenes. Because the reactivity of different terpenes with $\mathrm{OH}$ radicals and ozone differs several orders of magnitude (Atkinson and Arey, 2003a, b; Calogirou et al., 1999), for reliable air quality simulations, it is highly relevant to consider the variations in the composition of emitted terpene blends as well. There are multiple factors that can affect the composition of the emitted compounds, and we provide here only a brief overview of the key determinants.

In terpene-storing species, it is well-known that different genotypes have varying foliage terpene compositions (e.g., Canard et al., 1997; Hayashi and Komae, 1974; Tobolski and Hanover, 1971). In non-storing species, it has also been demonstrated that genotype affects the emission compositions, reflecting differences in the expression of various terpene synthases. For instance, in Mediterranean evergreen sclerophyll Quercus ilex, monoterpene emissions of some populations are dominated by $\alpha$-pinene and $\beta$-pinene, while in other populations by limonene (Niinemets et al., 2002c; Staudt et al., 2001b). Analogous observations have been made for another Mediterranean sclerophyll Quercus suber (Staudt et al., 2004). Apart from the strong genetic component, there is evidence of environmental effects such as water, nutrient and light availabilities on terpene compositions in terpene-storing species (Firmage, 1981; Letchamo et al., 1994; Merk et al., 1988; Schiller, 1993; Voirin et al., 1990).

Leaf age and seasonality have also been shown to affect the composition of stored terpenes (Hall and Langenheim, 1986; Rohloff, 1999). In addition, variation in the composition of emissions during the season has been demonstrated for terpene-storing and non-storing species (Bertin et al., 1997; He et al., 2000; Kuhn et al., 2004; Llusià and Peñuelas, 2000; Sabillón and Cremades, 2001; Staudt et al., 1997, 2000). Interestingly, in constitutive isoprene emitters, young leaves that do not yet have developed the capacity for isoprene emission may be significant monoterpene emitters (Brilli et al., 2009; Kuhn et al., 2004). With development of isoprene emission capacity, monoterpene emission rates 
decrease and the emissions cease in fully mature non-stressed leaves (Brilli et al., 2009; Kuhn et al., 2004).

In addition, growth under elevated $\mathrm{CO}_{2}$ can modify the composition of emissions in non-storing species (Loreto et al., 2001). So far, such variations are imperfectly understood, but may reflect selective expression of different monoterpene synthases in different conditions (Loreto et al., 2001). As discussed in Sect. 2.3, environmental and biotic stress elicits expression of a variety of mono- and sesquiterpenes, and thus, stress-induced emissions typically have different compositions than constitutive emissions.

In addition to the biological factors, emission compositions in species without specialized storage can transiently change due to differences in compound physico-chemical characteristics (Eq. 8, Table 1), for instance, after dark-light transfers. Due to differences in the capacity for non-specific storage, compounds with lower volatility take longer to reach a steady-state tissue concentration. Thus, after switching on the light, the emissions will be initially dominated by compounds with greater volatility, while after switching off the light, emissions will be dominated by compounds with lower volatility (Niinemets and Reichstein, 2002). In addition, analogous effects can occur after rapid changes in the rate of monoterpene synthesis such as after light or temperature change. Such physico-chemical effects emphasize the importance of analyzing the emission compositions in the steady-state.

These data collectively demonstrate that variations in emission composition occur among the populations of the same species and can also occur in dependence on environmental drivers and seasonality. We plead that the information of the composition of emitted compounds be published together with the sum of the emissions $\left(E_{\mathrm{S}}\right)$.

\subsection{Scaling $E_{S}$ in models}

$E_{\mathrm{S}}$ in the emission models have been originally defined as species-specific values on the leaf scale (Guenther et al., 1991, 1993). These species-specific $E_{\mathrm{S}}$ values of dominant species have been employed to simulate regional emissions (Guenther et al., 1994, 1996b; Keenan et al., 2009). Further plant functional type specific (Guenther et al., 1995), and landscape-level (Guenther et al., 1999) emission potentials both still defined on the basis of leaf area were constructed. Ultimately, average canopy-level integrated emission potentials have been defined (Guenther et al., 2006). These canopy-level values were expressed on the basis of ground surface area differently from all previous $E_{\mathrm{S}}$ definitions (Guenther et al., 2006). Larger-scale emission potentials can be estimated from leaf-scale emission potentials using up-scaling models or by direct measurements of emission fluxes using micrometeorological techniques. As the upscaled values are outcomes of models, the aggregated emission potentials derived from leaf-level data are subject to vary with the algorithms used for integration of isoprenoid fluxes.
On the other hand, deriving the larger-scale emission potentials from flux measurements also requires several critical assumptions. Here we analyze the way $E_{\mathrm{S}}$ values are used and aggregated in different model schemes, potentials and limitations of various scaling routines and the compatibility of aggregated $E_{\mathrm{S}}$ values scaled up in various manner. We also shortly analyze the potentials and limitations of derivation of the large-scale emission potentials from the emission flux measurements.

\subsubsection{Leaf-level emission potentials scaled to canopy, landscape and biome}

Leaf-scale species-specific estimates of $E_{\mathrm{S}}$ can be directly used to simulate canopy and landscape level BVOC emission fluxes using soil-vegetation-atmosphere transfer (SVAT) models (e.g., Baldocchi and Meyers, 1998; Baldocchi et al., 1999) similar to the schemes widely used for simulation of plant carbon gain (Caldwell et al., 1986; Falge et al., 1997; Ryel, 1993). SVAT models are typically 1-D layered models or 3-D models that describe the variation in light, temperature and humidity in dependence on the amount of leaf area and leaf area distribution of the vegetation (e.g., Baldocchi, 1991; Baldocchi et al., 1999; Cescatti and Niinemets, 2004).

In addition to employing appropriate light, temperature and $\mathrm{CO}_{2}$ response functions (Eqs. 1-7), a series of biological factors such as leaf age, and long- and short-term acclimation responses in $E_{\mathrm{S}}$ are important to consider (Grote, 2007; Niinemets et al., 2010). For accurate integration, distribution of foliage of different emitting species within the canopy is needed. Canopy models with varying complexity can be used in integration schemes, e.g., models including spatial aggregation and 3-D heterogeneity vs. simple Lambert-Beer models with random dispersion of foliage elements (Baldocchi, 1997; Cescatti and Niinemets, 2004). Although $E_{S}$ is the key predictor of the emission potential of given vegetation, the structure of the canopy model, as well as the quality of leaf area and canopy architecture data can potentially introduce as much or even more variation in predicted emission fluxes as the prescribed $E_{\mathrm{S}}$ values (Grote, 2007; Guenther et al., 2006).

At the biome- and global-scales, emission potentials are typically determined for plant functional types (PFT), $E_{\mathrm{S}, \mathrm{PFT}}$, based on the species-specific $E_{\mathrm{S}}$ estimates obtained from screening studies conducted all across the world (Arneth et al., 2007; Guenther et al., 1995, 2006). These functional-type specific $E_{\mathrm{S}}$ estimates significantly simplify the large-scale integration of emission fluxes. However, the accuracy of $E_{\mathrm{S}, \mathrm{PFT}}$ values depends on the way the weighted average of species-specific $E_{\mathrm{S}}$ values is obtained. While global average $E_{\mathrm{S}, \mathrm{PFT}}$ values can be derived for each PFT, species composition within a given PFT will significantly affect the predicted emissions. For instance, both deciduous North-American species Fagus grandifolia and Quercus alba will fall in broad-leaved deciduous tree PFT, but 
F. grandifolia does not emit isoprene, while $Q$. alba is a strong isoprene emitter. Thus, isoprene emissions of areas dominated by Fagus will be overestimated by average $E_{\mathrm{S}, \mathrm{PFT}}$ for broad-leaved forests, while the emissions from areas dominated by Quercus will be underestimated. The spatial resolution of emission inventories can be significantly improved by including available vegetation species coverage data (Guenther et al., 2006). In any case, it is important to keep in mind that any PFT-level emission potential is a modeled characteristic that depends both on leaf-level $E_{\mathrm{S}}$ values as well as on species coverage estimates. Errors in species coverage estimates can potentially bias the emission predictions as much as errors in prescription of $E_{\mathrm{S}}$, and become potentially relevant when vegetation composition changes due to changes in environmental conditions (Schurgers et al., 2009b).

In large-scale emission models, use of layered or 3-D models that specify environmental conditions for each layer or 3-D canopy element, voxel, is complicated by the need for high amount of detailed structural information for model parameterization. Yet, typically only spatial information for integrated traits such as canopy leaf area index and plant functional type is available. As an alternative to the detailed multi-layered models, big-leaf canopy models have been developed that approximate the canopy as a single big-leaf (Amthor, 1994; Lloyd et al., 1995). The key limitation of single big-leaf models is associated with inherent non-linearity of plant physiological responses to light and temperature. As the result, simple integration that does not consider that under sunny conditions there are sunlit and shaded foliage at any location in the canopy, overestimates the true fluxes: this is a mathematical consequence of Jensen's inequality theorem for concave functions (Niinemets and Anten, 2009 for a review). Such integration problems are partly overcome by development of two big-leaf models, consisting of a sunlit and a shaded big-leaf (Dai et al., 2004; de Pury and Farquhar, 1997).

Many big-leaf type models assume that the responses of the entire canopy to light and temperature can be approximated with functions similar to those used for single leaves. Certain "optimum" variation in foliage physiological potentials within the canopy is assumed, and thus, only the upper canopy leaf physiological potentials are used for analytical integration of whole canopy responses to above-canopy environmental conditions (Amthor, 1994; Dai et al., 2004; de Pury and Farquhar, 1997). In these models, the "optimum" variation is defined as linear decrease of foliage physiological potentials with long-term light availability from top to bottom of the canopy (Amthor, 1994; Dai et al., 2004; de Pury and Farquhar, 1997). With such assumption, the typical $E_{\mathrm{S}}$ values estimated for high-light exposed foliage, and $E_{\mathrm{S}, \mathrm{PFT}}$ values derived from these, can be used in the areadependent integration of large-scale fluxes. Such big-leaf approaches have been used in global isoprene and monoterpene simulations with LPJ-GUESS (Arneth et al., 2007, 2008a;
Schurgers et al., 2009a). So far, the condition of "optimal" variation of $E_{\mathrm{S}}$ through the canopy still awaits experimental verification, although for photosynthesis, we have learned that the variation is not satisfying the optimality criterion (Friend, 2001; Niinemets and Anten, 2009).

\subsubsection{Canopy-level emission potentials in integration schemes}

In the integration schemes outlined above, $E_{\mathrm{S}}$ values used are still leaf-scale emission potentials determined for unshaded foliage. Alternatively, in the recent isoprene emission model MEGAN, canopy-scale isoprene emission potential, $E_{\text {can }}$ was defined (Guenther et al., 2006) that is not only standardized for temperature and light as $E_{\mathrm{S}}$ traditionally was, but also for leaf area index (LAI) and for many biological factors. In MEGAN, canopy-level isoprene emission fluxes are calculated combining $E_{\text {can }}$ with empirical relationships between above-canopy average incident quantum flux density and temperature (Guenther et al., 2006).

Two different approaches are currently used to derive $E_{\text {can }}$ estimates. $E_{\text {can }}$ values can be based on available leaf-level $E_{\mathrm{S}}$ estimates for given species that are further combined with a canopy model to yield values of $E_{\text {can }}$ (Guenther et al., 2006). PFT-specific values of $E_{\text {can }}$ can be further derived combining $E_{\mathrm{S}}$ estimates of species belonging to given plant functional type and linking these again to a canopy model (Guenther et al., 2006). Alternatively, $E_{\text {can }}$ determinations can take advantage of the circumstance that net isoprenoid emission fluxes (emission of BVOC by vegetation minus decomposition in the ambient atmosphere as well as deposition to the canopy) can be measured by a variety of micrometeorological techniques, from analysis of gradients to relaxed eddy accumulation (REA) and eddy covariance (Baldocchi et al., 1999; Fuentes and Wang, 1999; Fuentes et al., 1999; Graus et al., 2006; Guenther et al., 1996a; Huber et al., 1999; Karl et al., 2002, 2007; Kim et al., 2009; Rinne et al., 2002; Spanke et al., 2001; Spirig et al., 2005). Thus, $E_{\text {can }}$ estimations can skip the tedious step of leaf to canopy integration that can be error-prone and uncertainty-inducing if numerous assumptions need to be made due to practical reasons.

However, the key question is how one can generalize from a set of studied ecosystems with given canopy structure and emitting species composition to other ecosystems with differing structure to derive landscape- and regional-scale emission fluxes. Obviously, if information of compound decomposition and deposition is available, one can derive an estimate of the canopy-emission potential, $E_{\text {can,flux }}$, from the flux measurements. However, out of the large number of measurements obtained by eddy-flux measurements, only few data may correspond to the "standardized" light and temperature defining a specific $E_{\mathrm{can} \text {,flux }}$ value. Thus, inverse modeling approaches are needed that solve for the value of $E_{\mathrm{can}, f l u x}$ best describing the whole set of measurements, i.e. satisfying the condition specified by Eq. (13). Yet, 
the value of $E_{\text {can,flux }}$ obtained will critically depend on the model structure assumed. Inverting a layered model to derive leaf-area weighted average emission potential is clearly impractical because of lack of bijection and accordingly, due to too many assumptions required. Alternatively, fitting canopy emissions to light and temperature above the canopy based on Eqs. (2) and (3), can yield values of initial quantum yield of emission (Eq. 2) and $E_{\text {can,flux }}$, among other parameters, specific to a given canopy. However, these parameters, in particular, the quantum yield of isoprenoid emission and $E_{\text {can,flux }}$ are subject to vary with canopy structure and potentially also with meteorological conditions, e.g., overcast vs. sunny days (Gu et al., 2003 for model analysis of whole canopy responses to direct vs. diffuse solar radiation). As flux measurements are often not conducted in stands having a "standard" LAI, converting the values of quantum yield and $E_{\text {can,flux }}$ to a standard LAI used in MEGAN would again require implementation of a canopy model. Inverse modeling procedures are becoming standardized in $\mathrm{CO}_{2}$-flux community (Carvalhais et al., 2008; Lasslop et al., 2008), but so far no common protocol has been agreed upon in BVOC emission community.

In summary, in large-scale integration schemes, it is highly relevant to clearly specify how the emission potential used for scaling the emission fluxes is determined. Integration models currently include both emission potentials that are directly based on leaf-level measurements and emission potentials that include a great deal of modeling. It is important to consider that these different emission potentials cannot be used interchangeably in different models. Care should be taken in applying the modeled and aggregated emission potentials, e.g., as $E_{\text {can }}$ applied in MEGAN (Guenther et al., 2006). Any change in light and temperature response functions applied in the emission model, and modification of time-resolution of climatic drivers would require re-computation of $E_{\text {can }}$ values.

\section{Outlook}

The emission models used worldwide to simulate volatile isoprenoid emission fluxes from vegetation for further use in atmospheric chemistry models are largely based on Guenther et al. (1991, 1993) algorithms. The strength of these algorithms has been the conceptual simplicity provided to modelers in that they need only the standardized emission rate, $E_{\mathrm{S}}$, and being able to simulate the emission fluxes using the light and temperature functions specified by Guenther et al. (1991, 1993), for which input data are readily worldwide available. However, since the original development of the Guenther at al. algorithms significant variations in plant responses to environmental drivers light and temperature, and to so far unaccounted environmental drivers such as $\mathrm{CO}_{2}$, have been highlighted, and emission induction by biotic and abiotic stresses and modifications in emission compositions have been demonstrated. Recent studies have also observed important variability in the share in the emission controls between compound synthesis and physico-chemical factors. On the basis of this knowledge, the accuracy of source modeling can be improved. Of course, inclusion of further details necessarily carries larger parameterization burden, but making this effort might be worthwhile when the accuracy of emission source estimates is critical to improve, e.g., in extrapolating to future environments (Arneth and Niinemets, 2010; Arneth et al., 2008b; Young et al., 2009). Apart from the sources of variation resulting from factors controlling the emissions, definitions of $E_{\mathrm{S}}$ differ depending on the underlying model algorithms and degree of aggregation, and can be a chief reason for large between-model discrepancies of simulated emission totals (e.g., Arneth et al., 2008a for a compilation of respective global extrapolation exercises). Our purpose in writing this paper was to provide greater depth in the understanding for those who wish to simulate isoprenoid emissions, and to stimulate the development of novel approaches which include the contemporary understanding of emission controls in future emission predictions.

Acknowledgements. This paper arose as the result of stimulating discussions at the European Science Foundation (VOCBAS and INTROP programmes) science meeting Biogenic Volatile Organic Compounds: Sources and Fates in a Changing World, 2 October5 October 2007, Montpellier, France. The authors' work on BVOC emissions has been supported by the Estonian Ministry of Education and Research (grant SF1090065s07), the Estonian Science Foundation (grant 7645), the US National Science Foundation and the US Environmental Protection Agency, the join collaborative project between Spanish CSIC and the Estonian Academy of Sciences, the Spanish Government (grants CGL2006-04025/BOS and Consolider-Ingenio Montes CSD2008-00040), the Catalan government (grant SGR2009-458), the Human Frontier Science Programme, the Swedish Research Councils VR and Formas. We thank Rüdiger Grote, Alex Guenther, Peter Harley, Trevor Keenan, Thomas Karl, Manuel Lerdau and Georg Wohlfahrt for illuminating comments on the manuscript.

Edited by: G. Wohlfahrt

\section{References}

Alonso, W. R. and Croteau, R.: Prenyltransferases and cyclases, in: Enzymes of secondary metabolism, edited by: Lea, P. J., Methods in plant biochemistry, 9, Academic Press, London - San Diego - New York - Boston - Sydney - Tokyo - Toronto, 239-260, 1993.

Amthor, J. S.: Scaling $\mathrm{CO}_{2}$-photosynthesis relationships from the leaf to the canopy, Photosynth. Res., 39, 321-350, 1994.

Arimura, G.-I., Matsui, K., and Takabayashi, J.: Chemical and molecular ecology of herbivore-induced plant volatiles: proximate factors and their ultimate functions, Plant Cell Physiol., 50, 911-923, 2009.

Arneth, A., Niinemets, Ü., Pressley, S., Bäck, J., Hari, P., Karl, T., Noe, S., Prentice, I. C., Serça, D., Hickler, T., Wolf, A., 
and Smith, B.: Process-based estimates of terrestrial ecosystem isoprene emissions: incorporating the effects of a direct $\mathrm{CO}_{2}$-isoprene interaction, Atmos. Chem. Phys., 7, 31-53, doi:10.5194/acp-7-31-2007, 2007.

Arneth, A., Monson, R. K., Schurgers, G., Niinemets, Ü., and Palmer, P. I.: Why are estimates of global terrestrial isoprene emissions so similar (and why is this not so for monoterpenes)?, Atmos. Chem. Phys., 8, 4605-4620, doi:10.5194/acp-8-46052008, 2008a.

Arneth, A., Schurgers, G., Hickler, T., and Miller, P. A.: Effects of species composition, land surface cover, $\mathrm{CO}_{2}$ concentration and climate on isoprene emissions from European forests, Plant Biol., 10, 150-152, 2008b.

Arneth, A. and Niinemets, Ü.: Induced BVOCs: how to bug our models?, Trends Plant Sci., 15, 118-125, 2010.

Atkinson, R. and Arey, J.: Atmospheric degradation of volatile organic compounds, Chem. Rev., 103, 4605-4638, 2003 a.

Atkinson, R. and Arey, J.: Gas-phase tropospheric chemistry of biogenic volatile organic compounds: a review, Atmos. Environ., 37, 197-219, 2003b.

Baldocchi, D.: Measuring and modelling carbon dioxide and water vapour exchange over a temperate broad-leaved forest during the 1995 summer drought, Plant Cell Environ., 20, 1108-1122, 1997.

Baldocchi, D. and Meyers, T.: On using eco-physiological, micrometeorological and biogeochemical theory to evaluate carbon dioxide, water vapor and trace gas fluxes over vegetation: a perspective, Agr. Forest Meteorol., 90, 1-25, 1998.

Baldocchi, D. D.: Canopy control of trace gas emissions, in: Trace gas emissions by plants, edited by: Sharkey, T. D., Holland, E. A., and Mooney, H. A., Physiological ecology, A series of monographs, texts, and treatises, Academic Press, Inc., San Diego New York - Boston - London - Sydney - Tokyo - Toronto, 293333, 1991.

Baldocchi, D. D., Fuentes, J. D., Bowling, D. R., Turnipseed, A. A., and Monson, R. K.: Scaling isoprene fluxes from leaves to canopies: test cases over a boreal aspen and a mixed species temperate forest, J. Appl. Meteorol., 38, 885-898, 1999.

Beauchamp, J., Wisthaler, A., Hansel, A., Kleist, E., Miebach, M., Niinemets, Ü., Schurr, U., and Wildt, J.: Ozone induced emissions of biogenic VOC from tobacco: relations between ozone uptake and emission of LOX products, Plant Cell Environ., 28, 1334-1343, 2005.

Bertin, N. and Staudt, M.: Effect of water stress on monoterpene emissions from young potted holm oak (Quercus ilex L.) trees, Oecologia, 107, 456-462, 1996.

Bertin, N., Staudt, M., Hansen, U., Seufert, G., Ciccioli, P., Foster, P., Fugit, J. L., and Torres, L.: Diurnal and seasonal course of monoterpene emissions from Quercus ilex (L.) under natural conditions - applications of light and temperature algorithms, Atmos. Environ., 31, 135-144, 1997.

Blande, J. D., Tiiva, P., Oksanen, E., and Holopainen, J. K.: Emission of herbivore-induced volatile terpenoids from two hybrid aspen (Populus tremula $\times$ tremuloides) clones under ambient and elevated ozone concentrations in the field, Global Change Biol., 13, 2538-2550, 2007.

Bowles, E. J.: The chemistry of aromatherapeutic oils, Allen \& Unwin, Crows Nest, NSW, Australia, 256 pp., 2003.

Brilli, F., Ciccioli, P., Frattoni, M., Prestininzi, M., Spanedda, A.
F., and Loreto, F.: Constitutive and herbivore-induced monoterpenes emitted by Populus $x$ euroamericana leaves are key volatiles that orient Chrysomela populi beetles, Plant Cell Environ., 32, 542-552, 2009.

Caldwell, M. M., Meister, H. P., Tenhunen, J. D., and Lange, O. L.: Canopy structure, light microclimate and leaf gas exchange of Quercus coccifera L. in a Portuguese macchia: measurements in different canopy layers and simulations with a canopy model, Trees, 1, 25-41, 1986.

Calogirou, A., Larsen, B. R., and Kotzias, D.: Gas-phase terpene oxidation products: a review, Atmos. Environ., 33, 1423-1439, 1999.

Canard, D., Perru, O., Tauzin, V., Devillard, C., and Bonhoure, J. P.: Terpene composition variations in diverse provenances of Cedrus libani (A.) Rich. and Cedrus atlantica Manet, Trees, 11, 504510, 1997.

Cardoza, Y. J., Alborn, H. T., and Tumlinson, J. H.: In vivo volatile emissions from peanut plants induced by simultaneous fungal infection and insect damage, J. Chem. Ecol., 28, 161-174, 2002.

Carvalhais, N., Reichstein, M., Seixas, J., Collatz, G. J., Pereira, J. S., Berbigier, P., Carrara, A., Granier, A., Montagnani, L., Papale, D., Rambal, S., Sanz, M. J., and Valentini, R.: Implications of carbon cycle steady state assumptions for biogeochemical modeling performance and inverse parameter retrieval, Global Biogeochem. Cycles, 22, GB2007, doi:10.1029/2007GB003033, 2008.

Cescatti, A. and Niinemets, Ü.: Sunlight capture. Leaf to landscape, in: Photosynthetic adaptation, Chloroplast to landscape, edited by: Smith, W. K., Vogelmann, T. C., and Chritchley, C., Ecological Studies, 178, Springer Verlag, Berlin, 42-85, 2004.

Chen, J. W., Harner, T., Schramm, K.-W., Quan, X., Xue, X. Y., and Kettrup, A.: Quantitative relationships between molecular structures, environmental temperatures and octanol/air partition coefficients of polychlorinated biphenyls, Comput. Biol. Chem., 27, 405-421, 2003.

Ciccioli, P., Fabozzi, C., Brancaleoni, E., Cecinato, A., Frattoni, M., Cieslik, S., Kotzias, D., Seufert, G., Foster, P., and Steinbrecher, R.: Biogenic emission from the Mediterranean pseudosteppe ecosystem present in Castelporziano, Atmos. Environ., 31, 167-175, 1997a.

Ciccioli, P., Fabozzi, C., Brancaleoni, E., Cecinato, A., Frattoni, M., Loreto, F., Kesselmeier, J., Schäfer, L., Bode, K., Torres, L., and Fugit, J.-L.: Use of the isoprene algorithm for predicting the monoterpene emission from the Mediterranean holm oak Quercus ilex L.: performance and limits of this approach, J. Geophys. Res., 102, 23319-23328, 1997b.

Copolovici, L. and Niinemets, Ü.: Salting-in and salting-out effects of ionic and neutral osmotica on limonene and linalool Henry's law constants and octanol/water partition coefficients, Chemosphere, 69, 621-629, doi:10.1016/j.chemosphere.2007.02.066, 2007.

Copolovici, L. O., Filella, I., Llusià, J., Niinemets, Ü., and Peñuelas, J.: The capacity for thermal protection of photosynthetic electron transport varies for different monoterpenes in Quercus ilex, Plant Physiol., 139, 485-496, 2005.

Copolovici, L. O. and Niinemets, Ü.: Temperature dependencies of Henry's law constants and octanol/water partition coefficients for key plant volatile monoterpenoids, Chemosphere, 61, 13901400, doi:10.1016/j.chemosphere.2005.05.003, 2005. 
Corchnoy, S. B., Arey, J., and Atkinson, R.: Hydrocarbon emissions from twelve urban shade trees of Los Angeles, California, air basin, Atmos. Environ., 26, 339-348, 1992.

Dai, Y.-J., Dickinson, R. E., and Wang, Y. P.: A two-big-leaf model for canopy temperature, photosynthesis, and stomatal conductance, J. Climate, 17, 2281-2299, 2004.

de Pury, D. G. G. and Farquhar, G. D.: Simple scaling of photosynthesis from leaves to canopies without the errors of big-leaf models, Plant Cell Environ., 20, 537-557, 1997.

Dindorf, T., Kuhn, U., Ganzeveld, L., Schebeske, G., Ciccioli, P., Holzke, C., Köble, R., Seufert, G., and Kesselmeier, J.: Significant light and temperature dependent monoterpene emissions from European beech (Fagus sylvatica L.) and their potential impact on the European volatile organic compound budget, J. Geophys. Res.-Atmos., 111, D16305, doi:10.1029/2005JD006751, 2006.

Duhl, T. R., Helmig, D., and Guenther, A.: Sesquiterpene emissions from vegetation: a review, Biogeosciences, 5, 761-777, doi:10.5194/bg-5-761-2008, 2008.

Eder, B. K., Davis, J. M., and Bloomfield, P.: A characterization of the spatiotemporal variability of non-urban ozone concentrations over the eastern United States, Atmos. Environ., 27, 2645-2668, 1993.

Engelhart, G. J., Asa-Awuku, A., Nenes, A., and Pandis, S. N.: $\mathrm{CCN}$ activity and droplet growth kinetics of fresh and aged monoterpene secondary organic aerosol, Atmos. Chem. Phys., 8, 3937-3949, doi:10.5194/acp-8-3937-2008, 2008.

Falge, E., Ryel, R. J., Alsheimer, M., and Tenhunen, J. D.: Effects of stand structure and physiology on forest gas exchange: a simulation study for Norway spruce, Trees, 11, 436-448, 1997.

Fiore, A. M., Jacob, D. J., Mathur, R., and Martin, R. V.: Application of empirical orthogonal functions to evaluate ozone simulations with regional and global models, J. Geophys. Res.-Atmos., 108, 4431, doi:10.1029/2002JD003151, 2003.

Firmage, D. H.: Environmental influences on the monoterpene variation in Hedeoma drummondii, Biochem. Syst. Ecol., 9, 53-58, 1981.

Fischbach, R. J., Zimmer, I., Steinbrecher, R., Pfichner, A., and Schnitzler, J.-P.: Monoterpene synthase activities in leaves of Picea abies (L.) Karst. and Quercus ilex L., Phytochemistry, 54, 257-265, 2000.

Friend, A. D.: Modelling canopy $\mathrm{CO}_{2}$ fluxes: are "big-leaf" simplifications justified?, Global Ecol. Biogeogr., 10, 603-619, 2001.

Fuentes, J. D. and Wang, D.: On the seasonality of isoprene emissions from a mixed temperate forest, Ecol. Appl., 9, 1118-1131, 1999.

Fuentes, J. D., Wang, D., and Gu, L.: Seasonal variations in isoprene emissions from a boreal aspen forest, J. Appl. Meteorol., 38, 855-869, 1999.

Funk, J. L., Giardina, C. P., Knohl, A., and Lerdau, M. T.: Influence of nutrient availability, stand age, and canopy structure on isoprene flux in a Eucalyptus saligna experimental forest, J. Geophys. Res.-Biogeo., 111, G02012, doi:10.1029/2005JG000085, 2006.

Graus, M., Hansel, A., Wisthaler, A., Lindinger, C., Forkel, R., Hauff, K., Klauer, M., Pfichner, A., Rappenglück, B., Steigner, D., and Steinbrecher, R.: A relaxed-eddy-accumulation (REA) method using an online gas-chromatographic technique and PTR-MS for the measurement of isoprenoid fluxes, Atmos.
Environ., 40, 43-54, 2006.

Gray, D. W., Lerdau, M. T., and Goldstein, A. H.: Influences of temperature history, water stress, and needle age on methylbutenol emissions, Ecology, 84, 765-776, 2003.

Grote, R., Mayrhofer, S., Fischbach, R. J., Steinbrecher, R., Staudt, M., and Schnitzler, J.-P.: Process-based modelling of isoprenoid emissions from evergreen leaves of Quercus ilex L., Atmos. Environ., 40, S152-S165, 2006.

Grote, R.: Sensitivity of volatile monoterpene emission to changes in canopy structure: a model-based exercise with a process-based emission model, New Phytol., 173, 550-561, doi:10.1111/j.1469-8137.2006.01946.x, 2007.

Grote, R. and Niinemets, Ü.: Modeling volatile isoprenoid emission - a story with split ends, Plant Biol., 10, 8-28, doi:10.1055/s2007-964975, 2008.

Grote, R., Lavoir, A.-V., Rambal, S., Staudt, M., Zimmer, I., and Schnitzler, J.-P.: Modelling the drought impact on monoterpene fluxes from an evergreen Mediterranean forest canopy, Oecologia, 160, 213-223, 2009.

Grote, R., Keenan, T., Lavoir, A.-V., and Staudt, M.: Process-based simulation of seasonality and drought stress in monoterpene emission models, Biogeosciences, 7, 257-274, doi:10.5194/bg7-257-2010, 2010.

Gu, L., Baldocchi, D. D., Wofsy, S. C., Munger, J. W., Michalsky, J. J., Urbanski, S. P., and Boden, T. A.: Response of a deciduous forest to the Mount Pinatubo eruption: enhanced photosynthesis, Science, 299, 2035-2038, 2003.

Guenther, A., Zimmerman, P. R., and Wildermuth, M.: Natural volatile organic compound emission rates for US woodland landscapes, Atmos. Environ., 28, 1197-1210, 1994.

Guenther, A., Hewitt, C. N., Erickson, D., Fall, R., Geron, C., Graedel, T., Harley, P., Klinger, L., Lerdau, M., McKay, W. A., Pierce, T., Scholes, B., Steinbrecher, R., Tallamraju, R., Taylor, J., and Zimmerman, P.: A global model of natural volatile compound emissions, J. Geophys. Res., 100, 8873-8892, 1995.

Guenther, A., Baugh, W., Davis, K., Hampton, G., Harley, P., Klinger, L., Vierling, L., Zimmerman, P., Allwine, E., Dilts, S., Lamb, B., Westberg, H., Baldocchi, D., Geron, C., and Pierce, T.: Isoprene fluxes measured by enclosure, relaxed eddy accumulation, surface layer gradient, mixed layer gradient, and mixed layer mass balance techniques, J. Geophys. Res.-Atmos., 101, 18555-18567, 1996a.

Guenther, A., Greenberg, J., Harley, P., Helmig, D., Klinger, L., Vierling, L., Zimmerman, P., and Geron, C.: Leaf, branch, stand and landscape scale measurements of volatile organic compound fluxes from US woodlands, Tree Physiol., 16, 17-24, $1996 \mathrm{~b}$.

Guenther, A., Zimmerman, P., Klinger, L., Greenberg, J., Ennis, C., Davis, K., Pollock, M., Westberg, H., Allwine, G., and Geron, C.: Estimates of regional natural volatile organic compound fluxes from enclosure and ambient measurements, J. Geophys. Res., 101, 1345-1359, 1996c.

Guenther, A.: Seasonal and spatial variations in natural volatile organic compound emissions, Ecol. Appl., 7, 34-45, 1997.

Guenther, A.: Modeling biogenic volatile organic compound emissions to the atmosphere, in: Reactive hydrocarbons in the atmosphere, edited by: Hewitt, C. N., Academic Press, San Diego, 41-94, 1999.

Guenther, A., Baugh, B., Brasseur, G., Greenberg, J., Harley, P., Klinger, L., Serça, D., and Vierling, L.: Isoprene emission 
estimates and uncertainties for the Central African EXPRESSO study domain, J. Geophys. Res.-Atmos., 104, 30625-30639, 1999.

Guenther, A., Karl, T., Harley, P., Wiedinmyer, C., Palmer, P. I., and Geron, C.: Estimates of global terrestrial isoprene emissions using MEGAN (Model of Emissions of Gases and Aerosols from Nature), Atmos. Chem. Phys., 6, 3181-3210, doi:10.5194/acp-63181-2006, 2006.

Guenther, A. B., Monson, R. K., and Fall, R.: Isoprene and monoterpene emission rate variability: observations with $E u$ calyptus and emission rate algorithm development, J. Geophys. Res., 96, 10799-10808, 1991.

Guenther, A. B., Zimmerman, P. R., Harley, P. C., Monson, R. K., and Fall, R.: Isoprene and monoterpene emission rate variability: model evaluations and sensitivity analyses, J. Geophys. Res., 98, 12609-12617, 1993.

Hakola, H., Rinne, J., and Laurila, T.: The hydrocarbon emission rates of tea-leafed willow (Salix phylicifolia), silver birch (Betula pendula) and European aspen (Populus tremula), Atmos. Environ., 32, 1825-1833, 1998.

Hakola, H., Laurila, T., Lindfors, V., Hellen, H., Gaman, A., and Rinne, J.: Variation of the VOC emission rates of birch species during the growing season, Boreal Environ. Res., 6, 237-249, 2001.

Hakola, H., Tarvainen, V., Bäck, J., Ranta, H., Bonn, B., Rinne, J., and Kulmala, M.: Seasonal variation of mono- and sesquiterpene emission rates of Scots pine, Biogeosciences, 3, 93-101, doi:10.5194/bg-3-93-2006, 2006.

Hall, G. D. and Langenheim, J. H.: Temporal changes in the leaf monoterpenes of Sequoia sempervirens, Biochem. Syst. Ecol., 14, 61-69, 1986.

Hanna, S. R., Russell, A. G., Wilkinson, J. G., Vukovich, J., and Hansen, D. A.: Monte Carlo estimation of uncertainties in BEIS3 emission outputs and their effects on uncertainties in chemical transport model predictions, J. Geophys. Res.-Atmos., 110, D01302, doi:10.1029/2004JD004986, 2005.

Hansen, U. and Seufert, G.: Temperature and light dependence of $\beta$-caryophyllene emission rates, J. Geophys. Res.-Atmos., 108, 4801, doi:10.1029/2003JD003853, 2003.

Harley, P., Guenther, A., and Zimmerman, P.: Effects of light, temperature and canopy position on net photosynthesis and isoprene emission from sweetgum (Liquidambar styraciflua) leaves, Tree Physiol., 16, 25-32, 1996.

Harley, P., Guenther, A., and Zimmerman, P.: Environmental controls over isoprene emission in deciduous oak canopies, Tree Physiol., 17, 705-714, 1997.

Harley, P., Fridd-Stroud, V., Greenberg, J., Guenther, A., and Vasconcellos, P.: Emission of 2-methyl-3-buten-2-ol by pines: a potentially large natural source of reactive carbon to the atmosphere, J. Geophys. Res., 103, 25479-25486, 1998.

Hayashi, N. and Komae, H.: Geographical variation in terpenes from Lindera umbellata and Lindera sericea, Phytochemistry, 13, 2171-2174, 1974.

He, C., Murray, F., and Lyons, T.: Seasonal variations in monoterpene emissions from Eucalyptus species, Chemosphere, Global Change Sci., 2, 65-76, 2000.

Heald, C. L., Wilkinson, M. J., Monson, R. K., Alo, C. A., Wang, G., and Guenther, A.: Response of isoprene emission to ambient $\mathrm{CO}_{2}$ changes and implications for global budgets, Global
Change Biol., 15, 1127-1140, 2009.

Helmig, D., Revermann, T., Pollmann, J., Kaltschmidt, O., Hernandez, A. J., Bocquet, F., and David, D.: Calibration system and analytical considerations for quantitative sesquiterpene measurements in air, J. Chromatogr. A, 1002, 193-211, 2003.

Herde, M., Gärtner, K., Köllner, T. G., Fode, B., Boland, W., Gershenzon, J., Gatz, C., and Tholl, D.: Identification and regulation of TPS04/GES, an Arabidopsis geranyllinalool synthase catalyzing the first step in the formation of the insect-induced volatile $\mathrm{C}_{16}$-homoterpene TMTT, Plant Cell, 20, 1152-1168, 2008.

Holzinger, R., Lee, A., McKay, M., and Goldstein, A. H.: Seasonal variability of monoterpene emission factors for a ponderosa pine plantation in California, Atmos. Chem. Phys., 6, 1267-1274, doi:10.5194/acp-6-1267-2006, 2006.

Huber, D. P. W., Philippe, R. N., Godard, K.-A., Sturrock, R. N., and Böhlmann, J.: Characterization of four terpene synthase cDNAs from methyl jasmonate-induced Douglas-fir, Pseudotsuga menziesii, Phytochemistry, 66, 1427-1439, 2005.

Huber, L., Laville, P., and Fuentes, J. D.: Uncertainties in isoprene emissions from a mixed deciduous forest estimated using a canopy microclimate model, J. Appl. Meteorol., 38, 899-912, 1999.

Janson, R. W.: Monoterpene emissions from Scots pine and Norwegian spruce, J. Geophys. Res., 98, 2839-2850, 1993.

Jones, C. A. and Rasmussen, R. A.: Production of isoprene by leaf tissue, Plant Physiol., 55, 982-987, 1975.

Kahl, J., Hoffmann, T., and Klockow, D.: Differentiation between de novo synthesized and constitutively released terpenoids from Fagus sylvatica, Phytochemistry, 51, 383-388, 1999.

Karl, T., Guenther, A., Turnipseed, A., Patton, E. G., and Jardine, K.: Chemical sensing of plant stress at the ecosystem scale, Biogeosciences, 5, 1287-1294, doi:10.5194/bg-5-1287-2008, 2008.

Karl, T. G., Spirig, C., Rinne, J., Stroud, C., Prevost, P., Greenberg, J., Fall, R., and Guenther, A.: Virtual disjunct eddy covariance measurements of organic compound fluxes from a subalpine forest using proton transfer reaction mass spectrometry, Atmos. Chem. Phys., 2, 279-291, doi:10.5194/acp-2-279-2002, 2002.

Karl, T. G., Christian, T. J., Yokelson, R. J., Artaxo, P., Hao, W. M., and Guenther, A.: The Tropical Forest and Fire Emissions Experiment: method evaluation of volatile organic compound emissions measured by PTR-MS, FTIR, and GC from tropical biomass burning, Atmos. Chem. Phys., 7, 5883-5897, doi:10.5194/acp-7-5883-2007, 2007.

Keenan, T., Niinemets, Ü., Sabate, S., Gracia, C., and Peñuelas, J.: Process based inventory of isoprenoid emissions from European forests: model comparisons, current knowledge and uncertainties, Atmos. Chem. Phys., 9, 4053-4076, doi:10.5194/acp-94053-2009, 2009.

Kesselmeier, J., Bode, K., Hofmann, U., Müller, H., Schäfer, L., Wolf, A., Ciccioli, P., Brancaleoni, E., Cecinato, A., Frattoni, M., Foster, P., Ferrari, C., Jacob, V., Fugit, J. L., Dutaur, L., Simon, V., and Torres, L.: Emission of short chained organic acids, aldehydes and monoterpenes from Quercus ilex L. and Pinus pinea L. in relation to physiological activities, carbon budget and emission algorithms, Atmos. Environ., 31, 119-133, 1997.

Kim, S., Karl, T., Helmig, D., Daly, R., Rasmussen, R., and Guenther, A.: Measurement of atmospheric sesquiterpenes by proton transfer reaction-mass spectrometry (PTR-MS), Atmos. Meas. Tech., 2, 99-112, doi:10.5194/amt-2-99-2009, 2009. 
Komenda, M. and Koppmann, R.: Monoterpene emissions from Scots pine (Pinus sylvestris): field studies of emission rate variabilities, J. Geophys. Res., 107, 4161, doi:10.1029/2001JD000691, 2002.

König, G., Brunda, M., Puxbaum, H., Hewitt, C. N., Duckham, S. C., and Rudolph, J.: Relative contribution of oxygenated hydrocarbons to the total biogenic VOC emissions of selected MidEuropean agricultural and natural plant species, Atmos. Environ., 29, 861-874, 1995.

Kuhn, U., Rottenberger, S., Biesenthal, T., Wolf, A., Schebeske, G., Ciccioli, P., Brancaleoni, E., Frattoni, M., Tavares, T. M., and Kesselmeier, J.: Isoprene and monoterpene emissions of Amazonian tree species during the wet season: direct and indirect investigations on controlling environmental functions, J. Geophys. Res., D107, 8071, doi:10.1029/2001JD000978, 2002.

Kuhn, U., Rottenberger, S., Biesenthal, T., Wolf, A., Schebeske, G., Ciccioli, P., and Kesselmeier, J.: Strong correlation between isoprene emission and gross photosynthetic capacity during leaf phenology of the tropical tree species Hymenaea courbaril with fundamental changes in volatile organic compounds emission composition during early leaf development, Plant Cell Environ., 27, 1469-1485, 2004.

Kulmala, M., Suni, T., Lehtinen, K. E. J., Dal Maso, M., Boy, M., Reissell, A., Rannik, Ü., Aalto, P., Keronen, P., Hakola, H., Bäck, J., Hoffmann, T., Vesala, T., and Hari, P.: A new feedback mechanism linking forests, aerosols, and climate, Atmos. Chem. Phys., 4, 557-562, doi:10.5194/acp-4-557-2004, 2004.

Lasslop, G., Reichstein, M., Kattge, J., and Papale, D.: Influences of observation errors in eddy flux data on inverse model parameter estimation, Biogeosciences, 5, 1311-1324, doi:10.5194/bg5-1311-2008, 2008.

Lehning, A., Zimmer, I., Steinbrecher, R., Brüggemann, N., and Schnitzler, J. P.: Isoprene synthase activity and its relation to isoprene emission in Quercus robur L. leaves, Plant Cell Environ., 22, 495-504, 1999.

Lerdau, M. and Throop, H. L.: Sources of variability in isoprene emission and photosynthesis in two species of tropical wet forest trees, Biotropica, 32, 670-676, 2000.

Letchamo, W., Marquard, R., Hölzl, J., and Gosselin, A.: Effects of water supply and light intensity on growth and essential oil of two Thymus vulgaris selections, Angew. Bot., 68, 83-88, 1994.

Lichtenthaler, H. K., Schwender, J., Disch, A., and Rohmer, M.: Biosynthesis of isoprenoids in higher plant chloroplasts proceeds via a mevalonate-independent pathway, FEBS Lett., 400, 271274, 1997.

Lloyd, J., Wong, S. C., Styles, J. M., Batten, D., Priddle, R., Turnbull, C., and McConchie, C. A.: Measuring and modelling whole-tree gas exchange, Aust. J. Plant Physiol., 22, 987-1000, 1995.

Llusià, J. and Peñuelas, J.: Seasonal patterns of terpene content and emission from seven Mediterranean woody species in field conditions, Am. J. Bot., 87, 133-140, 2000.

Logan, J. A.: Ozone in rural areas of the United States, J. Geophys. Res.-Atmos., 94, 8511-8532, 1989.

Loreto, F. and Sharkey, T. D.: A gas-exchange study of photosynthesis and isoprene emission in Quercus rubra L., Planta, 182, 523-531, 1990.

Loreto, F., Ciccioli, P., Brancaleoni, E., Cecinato, A., Frattoni, M., and Sharkey, T. D.: Different sources of reduced carbon contribute to form three classes of terpenoid emitted by Quercus ilex L. leaves, P. Natl. Acad. Sci. USA, 93, 9966-9969, 1996a.

Loreto, F., Ciccioli, P., Cecinato, A., Brancaleoni, E., Frattoni, M., Fabozzi, C., and Tricoli, D.: Evidence of the photosynthetic origin of monoterpenes emitted by Quercus ilex L. leaves by ${ }^{13} \mathrm{C}$ labeling, Plant Physiol., 110, 1317-1322, 1996b.

Loreto, F., Ciccioli, P., Cecinato, A., Brancaleoni, E., Frattoni, M., and Tricoli, D.: Influence of environmental factors and air composition on the emission of $\alpha$-pinene from Quercus ilex leaves, Plant Physiol., 110, 267-275, 1996c.

Loreto, F., Förster, A., Dürr, M., Csiky, O., and Seufert, G.: On the monoterpene emission under heat stress and on the increased thermotolerance of leaves of Quercus ilex L. fumigated with selected monoterpenes, Plant Cell Environ., 21, 101-107, 1998.

Loreto, F., Nascetti, P., Graverini, A., and Mannozzi, M.: Emission and content of monoterpenes in intact and wounded needles of the Mediterranean pine, Pinus pinea, Funct. Ecol., 14, 589-595, 2000.

Loreto, F., Fischbach, R. J., Schnitzler, J. P., Ciccioli, P., Brancaleoni, E., Calfapietra, C., and Seufert, G.: Monoterpene emission and monoterpene synthase activities in the Mediterranean evergreen oak Quercus ilex L. grown at elevated $\mathrm{CO}_{2}$, Global Change Biol., 7, 709-717, 2001.

Loreto, F., Centritto, M., Barta, C., Calfapietra, C., Fares, S., and Monson, R. K.: The relationship between isoprene emission rate and dark respiration rate in white poplar (Populus alba L.) leaves, Plant Cell Environ., 30, 662-669, 2007.

Loughner, C. P., Lary, D. J., Sparling, L. C., Cohen, R. C., DeCola, P., and Stockwell, W. R.: A method to determine the spatial resolution required to observe air quality from space, IEEE T. Geosci. Remote, 45, 1308-1314, 2007.

Magel, E., Mayrhofer, S., Müller, A., Zimmer, I., Hampp, R., and Schnitzler, J.-P.: Photosynthesis and substrate supply for isoprene biosynthesis in poplar leaves, Atmos. Environ., 40, S138S151, 2006.

Martin, D., Gershenzon, J., and Bohlmann, J.: Induction of volatile terpene biosynthesis and diurnal emission by methyl jasmonate in foliage of Norway spruce, Plant Physiol., 132, 1586-1599, 2003.

Martin, M. J., Stirling, C. M., Humphries, S. W., and Long, S. P.: A process-based model to predict the effects of climatic change on leaf isoprene emission rates, Ecol. Model., 131, 161-174, 2000.

Mayrhofer, S., Teuber, M., Zimmer, I., Louis, S., Fischbach, R. J., and Schnitzler, J.-P.: Diurnal and seasonal variation of isoprene biosynthesis-related genes in grey poplar leaves, Plant Physiol., 139, 474-484, 2005.

Mentel, T. F., Wildt, J., Kiendler-Scharr, A., Kleist, E., Tillmann, R., Dal Maso, M., Fisseha, R., Hohaus, T., Spahn, H., Uerlings, R., Wegener, R., Griffiths, P. T., Dinar, E., Rudich, Y., and Wahner, A.: Photochemical production of aerosols from real plant emissions, Atmos. Chem. Phys., 9, 4387-4406, doi:10.5194/acp9-4387-2009, 2009.

Merk, L., Kloos, M., Schönwitz, R., and Ziegler, H.: Influence of various factors on quantitative composition of leaf monoterpenes of Picea abies (L.) Karst., Trees, 2, 45-51, 1988.

Meylan, W. M. and Howard, P. H.: Estimating octanol-air partition coefficients with octanol-water partition coefficients and Henry's law constants, Chemosphere, 61, 640-644, 2005. 
Mgalobilishvili, M. P., Khetsuriani, N. D., Kalandadze, A. N., and Sanadze, G. A.: Localization of isoprene biosynthesis in poplar leaf chloroplasts, Fiziol. Rast., 25, 1055-1061, 1978.

Monson, R. K. and Fall, R.: Isoprene emission from aspen leaves. Influence of environment and relation to photosynthesis and photorespiration, Plant Physiol., 90, 267-274, 1989.

Monson, R. K., Hills, A. J., Zimmerman, P. R., and Fall, R. R.: Studies of the relationship between isoprene emission rate and $\mathrm{CO}_{2}$ or photon-flux density using a real-time isoprene analyser, Plant Cell Environ., 14, 517-523, 1991.

Monson, R. K., Jaeger, C. H., Adams III, W. W., Driggers, E. M., Silver, G. M., and Fall, R.: Relationships among isoprene emission rate, photosynthesis, and isoprene synthase activity as influenced by temperature, Plant Physiol., 98, 1175-1180, 1992.

Monson, R. K., Trahan, N., Rosenstiel, T. N., Veres, P., Moore, D., Wilkinson, M., Norby, R. J., Volder, A., Tjoelker, M. G., Briske, D. D., Karnosky, D. F., and Fall, R.: Isoprene emission from terrestrial ecosystems in response to global change: minding the gap between models and observations, Philos. T. Roy. Soc. Lond. A, 365, 1677-1695, 2007.

Niinemets, Ü., Tenhunen, J. D., Harley, P. C., and Steinbrecher, R.: A model of isoprene emission based on energetic requirements for isoprene synthesis and leaf photosynthetic properties for Liquidambar and Quercus, Plant Cell Environ., 22, 13191336, 1999.

Niinemets, Ü., Hauff, K., Bertin, N., Tenhunen, J. D., Steinbrecher, R., and Seufert, G.: Monoterpene emissions in relation to foliar photosynthetic and structural variables in Mediterranean evergreen Quercus species, New Phytol., 153, 243-256, 2002a.

Niinemets, Ü. and Reichstein, M.: A model analysis of the effects of nonspecific monoterpenoid storage in leaf tissues on emission kinetics and composition in Mediterranean sclerophyllous Quercus species, Global Biogeochem. Cycles, 16, 1110, doi:1110.1029/2002GB001927, 2002.

Niinemets, Ü., Reichstein, M., Staudt, M., Seufert, G., and Tenhunen, J. D.: Stomatal constraints may affect emission of oxygenated monoterpenoids from the foliage of Pinus pinea, Plant Physiol., 130, 1371-1385, 2002b.

Niinemets, Ü., Seufert, G., Steinbrecher, R., and Tenhunen, J. D.: A model coupling foliar monoterpene emissions to leaf photosynthetic characteristics in Mediterranean evergreen Quercus species, New Phytol., 153, 257-276, 2002c.

Niinemets, Ü. and Reichstein, M.: Controls on the emission of plant volatiles through stomata: sensitivity or insensitivity of the emission rates to stomatal closure explained, J. Geophys. Res.Atmos., 108, 4208, doi:4210.1029/2002JD002620, 2003.

Niinemets, Ü.: Costs of production and physiology of emission of volatile leaf isoprenoids, in: Advances in Plant Physiology, edited by: Hemantaranjan, A., Scientific Publishers, Jodhpur, 233-268, 2004.

Niinemets, Ü., Loreto, F., and Reichstein, M.: Physiological and physico-chemical controls on foliar volatile organic compound emissions, Trends Plant Sci., 9, 180-186, 2004.

Niinemets, Ü.: Photosynthesis and resource distribution through plant canopies, Plant Cell Environ., 30, 1052-1071, 2007.

Niinemets, Ü.: Getting hold of terpene emissions from vegetation, ILeaps Newsletter, 5, 40-42, 2008.

Niinemets, Ü. and Anten, N. P. R.: Packing photosynthesis machinery: from leaf to canopy, in: Photosynthesis in silico: understanding complexity from molecules to ecosystems, edited by: Laisk, A., Nedbal, L., and Govindjee, Advances in photosynthesis and respiration, Springer Verlag, 29, Berlin, 363-399, 2009.

Niinemets, Ü.: Mild versus severe stress and BVOCs: thresholds, priming and consequences, Trends Plant Sci., 15, 145-153, 2010.

Niinemets, Ü., Arneth, A., Kuhn, U., Monson, R. K., Peñuelas, J., and Staudt, M.: The emission factor of volatile isoprenoids: stress, acclimation, and developmental responses, Biogeosciences Discuss., 7, 1529-1574, doi:10.5194/bgd-7-15292010, 2010.

Noe, S. M., Ciccioli, P., Brancaleoni, E., Loreto, F., and Niinemets, $\ddot{U}$.: Emissions of monoterpenes linalool and ocimene respond differently to environmental changes due to differences in physico-chemical characteristics, Atmos. Environ., 40, 46494662, 2006.

Noe, S. M., Copolovici, L., Niinemets, Ü., and Vaino, E.: Foliar limonene uptake scales positively with leaf lipid content: "nonemitting" species absorb and release monoterpenes, Plant Biol., 10, 129-137, doi:10.1055/s-2007-965239, 2008.

Noe, S. M., Niinemets, Ü., and Schnitzler, J.-P.: Modeling the temporal dynamics of monoterpene emission by isotopic labeling in Quercus ilex leaves, Atmos. Environ., 44, 392-399, 2010.

Ortega, J., Helmig, D., Guenther, A., Harley, P., Pressley, S., and Vogel, C.: Flux estimates and $\mathrm{OH}$ reaction potential of reactive biogenic volatile organic compounds (BVOCs) from a mixed northern hardwood forest, Atmos. Environ., 41, 54795495, 2007.

Owen, S., Boissard, C., Street, R. A., Duckham, S. C., Csiky, O., and Hewitt, C. N.: Screening of 18 Mediterranean plant species for volatile organic compound emissions, Atmos. Environ., 31, 101-117, 1997.

Owen, S. M., Boissard, C., Hagenlochera, B., and Hewitt, C. N.: Field studies of isoprene emissions from vegetation in the Northwest Mediterranean region, J. Geophys. Res.-Atmos., 103, 25499-25511, 1998.

Owen, S. M. and Hewitt, C. N.: Extrapolating branch enclosure measurements to estimates of regional scale biogenic VOC fluxes in the northwestern Mediterranean basin, J. Geophys. Res.-Atmos., 105, 11573-11583, 2000.

Owen, S. M., Boissard, C., and Hewitt, C. N.: Volatile organic compounds (VOCs) emitted from 40 Mediterranean plant species: VOC speciation and extrapolation to habitat scale, Atmos. Environ., 35, 5393-5409, 2001.

Owen, S. M., Harley, P., Guenther, A., and Hewitt, C. N.: Light dependency of VOC emissions from selected Mediterranean plant species, Atmos. Environ., 36, 3147-3159, 2002.

Owen, S. M., MacKenzie, A. R., Stewart, H., Donovan, R., and Hewitt, C. N.: Biogenic volatile organic compound (VOC) emission estimates from an urban tree canopy, Ecol. Appl., 13, 927-938, 2003.

Paluch, G., Grodnitzky, J., Bartholomay, L., and Coats, J.: Quantitative structure-activity relationship of botanical sesquiterpenes: spatial and contact repellency to the yellow fever mosquito, Aedes aegypti, J. Agr. Food Chem., 57, 7618-7625, 2009.

Paré, P. W. and Tumlinson, J. H.: Cotton volatiles synthesized and released distal to the site of insect damage, Phytochemistry, 47, 521-526, 1998. 
Paré, P. W. and Tumlinson, J. H.: Plant volatiles as a defense against insect herbivores, Plant Physiol., 121, 325-331, 1999.

Peñuelas, J. and Llusià, J.: Effects of carbon dioxide, water supply, and seasonality on terpene content and emission by Rosmarinus officinalis, J. Chem. Ecol., 23, 979-993, 1997.

Peñuelas, J. and Llusià, J.: Seasonal emission of monoterpenes by the Mediterranean tree Quercus ilex in field conditions: relations with photosynthetic rates, temperature and volatility, Physiol. Plant., 105, 641-647, 1999.

Peñuelas, J., Filella, I., Seco, R., and Llusià, J.: Increase in isoprene and monoterpene emissions after re-watering of droughted Quercus ilex seedlings, Biol. Plant., 53, 351-354, 2009.

Peñuelas, J. and Staudt, M.: BVOCs and global change, Trends Plant Sci., 15, 133-144, 2010.

Pétron, G., Harley, P., Greenberg, J., and Guenther, A.: Seasonal temperature variations influence isoprene emission, Geophys. Res. Lett., 28, 1707-1710, 2001.

Pinto, D. M., Blande, J. D., Nykänen, R., Dong, W.-X., Nerg, A.M., and Holopainen, J. K.: Ozone degrades common herbivoreinduced plant volatiles: does this affect herbivore prey location by predators and parasitoids?, J. Chem. Ecol., 33, 683-694, 2007.

Pio, C. A., Nuñes, T. V., and Brito, S.: Volatile hydrocarbon emissions from common and native species of vegetation in Portugal, in: Proceedings of the joint Workshop of CEC/BIATEX of EUROTRAC, General Assessment of Biogenic Emissions and Deposition of Nitrogen Compounds, Sulfur compounds and Oxidants in Europe, edited by: Slanina, J., Angeletti, G., and Beilke, S., Air Pollution Research Report, 47, EC, Directorate-General for Science, Research and Development Aveiro, Portugal, 291298, 1993

Pio, C. A., Silva, P. A., Cerqueira, M. A., and Nuñes, T. V.: Diurnal and seasonal emissions of volatile organic compounds from cork oak (Quercus suber) trees, Atmos. Environ., 39, 1817-1827, 2005.

Possell, M., Hewitt, C. N., and Beerling, D. J.: The effects of glacial atmospheric $\mathrm{CO}_{2}$ concentrations and climate on isoprene emissions by vascular plants, Global Change Biol., 11, 60-69, 2005.

Rapparini, F., Baraldi, R., Miglietta, F., and Loreto, F.: Isoprenoid emission in trees of Quercus pubescens and Quercus ilex with lifetime exposure to naturally high $\mathrm{CO}_{2}$ environment, Plant Cell Environ., 27, 381-391, 2004.

Rasulov, B., Hüve, K., Välbe, M., Laisk, A., and Niinemets, Ü.: Evidence that light, carbon dioxide and oxygen dependencies of leaf isoprene emission are driven by energy status in hybrid aspen, Plant Physiol., 151, 448-460, 2009.

Rinne, H. J. I., Guenther, A. B., Greenberg, J. P., and Harley, P. C.: Isoprene and monoterpene fluxes measured above Amazonian rainforest and their dependence on light and temperature, Atmos. Environ., 36, 2421-2426, 2002.

Rohloff, J.: Monoterpene composition of essential oil from peppermint (Mentha x piperita L.) with regard to leaf position using solid-phase microextraction and gas chromatography/mass spectrometry analysis, J. Agr. Food Chem., 47, 3782-3786, 1999.

Rosenstiel, T. N., Potosnak, M. J., Griffin, K. L., Fall, R., and Monson, R. K.: Increased $\mathrm{CO}_{2}$ uncouples growth from isoprene emission in an agriforest ecosystem, Nature, 421, 256-259, 2003.

Rosenstiel, T. N., Ebbets, A. L., Khatri, W. C., Fall, R., and Monson, R. K.: Induction of poplar leaf nitrate reductase: a test of extrachloroplastic control of isoprene emission rate, Plant Biol., 6, 12-21, 2004.

Ruuskanen, T. M., Hakola, H., Kajos, M. K., Hellén, H., Tarvainen, V., and Rinne, J.: Volatile organic compound emissions from Siberian larch, Atmos. Environ., 41, 5807-5812, 2007.

Ryel, R. J.: Light relations in tussock grasses as assessed with a new three-dimensional canopy photosynthesis model. Structure and function of foliage organization of a growth form prevalent in environments characterized by stress, Dr. rer. Nat. Thesis, JuliusMaximilians-Universität Würzburg, 172 pp., 1993.

Sabillón, D. and Cremades, L. V.: Diurnal and seasonal variation of monoterpene emission rates for typical Mediterranean species (Pinus pinea and Quercus ilex) from field measurements - relationship with temperature and PAR, Atmos. Environ., 35, 44194431, 2001.

Schade, G. W., Goldstein, A. H., Gray, D. W., and Lerdau, M. T.: Canopy and leaf level 2-methyl-3-buten-2-ol fluxes from a ponderosa pine plantation, Atmos. Environ., 34, 3535-3544, 2000.

Schiller, G.: Foliage resin composition of Cupressus sempervirens L. as affected by environmental factors, Silvae Genet., 42, 297303, 1993.

Schuh, G., Heiden, A. C., Hoffmann, T., Kahl, J., Rockel, P., Rudolph, J., and Wildt, J.: Emissions of volatile organic compounds from sunflower and beech: dependence on temperature and light intensity, J. Atmos. Chem., 27, 291-318, 1997.

Schurgers, G., Arneth, A., Holzinger, R., and Goldstein, A. H.: Process-based modelling of biogenic monoterpene emissions combining production and release from storage, Atmos. Chem. Phys., 9, 3409-3423, doi:10.5194/acp-9-3409-2009, 2009a.

Schurgers, G., Hickler, T., Miller, P. A., and Arneth, A.: European emissions of isoprene and monoterpenes from the Last Glacial Maximum to present, Biogeosciences, 6, 2779-2797, doi:10.5194/bg-6-2779-2009, 2009b.

Schwender, J., Zeidler, J., Gröner, R., Müller, C., Focke, M., Braun, S., Lichtenthaler, F. W., and Lichtenthaler, H. K.: Incorporation of 1-deoxy-D-xylulose into isoprene and phytol by higher plants and algae, FEBS Lett., 414, 129-134, 1997.

Seufert, G., Bartzis, J., Bombol, T., Ciccioli, P., Cieslik, S., Dlugi, R., Foster, P., Hewitt, C. N., Kesselmeier, J., Kotzias, D., Lenz, R., Manes, F., Perez Pastor, P., Steinbrecher, R., Torres, L., Valentini, R., and Versino, B.: An overview of the Castelporziano experiments, Atmos. Environ., 31, 5-17, 1997.

Shao, M., Czapiewski, K. V., Heiden, A. C., Kobel, K., Komenda, M., Koppmann, R., and Wildt, J.: Volatile organic compound emissions from Scots pine: mechanisms and description by algorithms, J. Geophys. Res., 106, 20483-20491, 2001.

Sharkey, T. D., Loreto, F., and Delwiche, C. F.: High carbon dioxide and sun/shade effects on isoprene emission from oak and aspen tree leaves, Plant Cell Environ., 14, 333-338, 1991.

Sharkey, T. D., Singsaas, E. L., Lerdau, M. T., and Geron, C. D.: Weather effects on isoprene emission capacity and applications in emissions algorithms, Ecol. Appl., 9, 1132-1137, 1999.

Singsaas, E. L., Laporte, M. M., Shi, J.-Z., Monson, R. K., Bowling, D. R., Johnson, K., Lerdau, M., Jasentuliytana, A., and Sharkey, T. D.: Kinetics of leaf temperature fluctuation affect isoprene emission from red oak (Quercus rubra) leaves, Tree Physiol., 19, 917-924, 1999. 
Singsaas, E. L. and Sharkey, T. D.: The effects of high temperature on isoprene synthesis in oak leaves, Plant Cell Environ., 23, 751757, 2000.

Smith, E. L.: The influence of light and carbon dioxide on photosynthesis, J. Gen. Physiol., 20, 807-830, 1937.

Spanke, J., Rannik, U., Forkel, R., Nigge, W., and Hoffmann, T.: Emission fluxes and atmospheric degradation of monoterpenes above a boreal forest: field measurements and modelling, Tellus, 53, 406-422, 2001.

Spirig, C., Neftel, A., Ammann, C., Dommen, J., Grabmer, W., Thielmann, A., Schaub, A., Beauchamp, J., Wisthaler, A., and Hansel, A.: Eddy covariance flux measurements of biogenic VOCs during ECHO 2003 using proton transfer reaction mass spectrometry, Atmos. Chem. Phys., 5, 465-481, doi:10.5194/acp-5-465-2005, 2005.

Spracklen, D. V., Bonn, B., and Carslaw, K. S.: Boreal forests, aerosols and the impacts on clouds and climate, Philos. Trans. Royal Soc. London A, 366, 4613-4626, 2008.

Staudinger, J. and Roberts, P. V.: A critical compilation of Henry's law constant temperature dependence relations for organic compounds in dilute aqueous solutions, Chemosphere, 44, 561-576, 2001.

Staudt, M. and Seufert, G.: Light-dependent emission of monoterpenes by holm oak (Quercus ilex L.), Naturwissenschaften, 82, 89-92, 1995.

Staudt, M., Bertin, N., Hansen, U., Seufert, G., Ciccioli, P., Foster, P., Frenzel, B., and Fugit, J. L.: Seasonal and diurnal patterns of monoterpene emissions from Pinus pinea (L.) under field conditions, Atmos. Environ., 31, 145-156, 1997.

Staudt, M. and Bertin, N.: Light and temperature dependence of the emission of cyclic and acyclic monoterpenes from holm oak (Quercus ilex L.) leaves, Plant Cell Environ., 21, 385-395, 1998.

Staudt, M., Bertin, N., Frenzel, B., and Seufert, G.: Seasonal variation in amount and composition of monoterpenes emitted by young Pinus pinea trees - implications for emission modeling, J. Atmos. Chem., 35, 77-99, 2000.

Staudt, M., Joffre, R., Rambal, S., and Kesselmeier, J.: Effect of elevated $\mathrm{CO}_{2}$ on monoterpene emission of young Quercus ilex trees and its relation to structural and ecophysiological parameters, Tree Physiol., 21, 437-445, 2001a.

Staudt, M., Mandl, N., Joffre, R., and Rambal, S.: Intraspecific variability of monoterpene composition emitted by Quercus ilex leaves, Can. J. Forest Res., 31, 174-180, 2001b.

Staudt, M., Joffre, R., and Rambal, S.: How growth conditions affect the capacity of Quercus ilex leaves to emit monoterpenes, New Phytol., 158, 61-73, 2003.

Staudt, M., Mir, C., Joffre, R., Rambal, S., Bonin, A., Landais, D., and Lumaret, R.: Isoprenoid emissions of Quercus spp. (Q. suber and $Q$. ilex) in mixed stands contrasting in interspecific genetic introgression, New Phytol., 163, 573-584, 2004.

Staudt, M. and Lhoutellier, L.: Volatile organic compound emission from holm oak infested by gypsy moth larvae: evidence for distinct responses in damaged and undamaged leaves, Tree Physiol., 27, 1433-1440, 2007.

Steinbrecher, R., Hauff, K., Rabong, R., and Steinbrecher, J.: Isoprenoid emission of oak species typical for the Mediterranean area: source strength and controlling variables, Atmos. Environ., 31, 79-88, 1997.
Steinbrecher, R., Hauff, K., Hakola, H., and Rössler, J.: A revised parameterisation for emission modelling of isoprenoids for boreal plants, in: Biogenic VOC emissions and photochemistry in the boreal regions of Europe: Biphorep, Final report, Contract No ENV4-CT95-0022, Air Pollution research report No 70, edited by: Laurila, T. and Lindfors, V., Office for Official Publications of the European Communities, Luxembourg, 29-44, 1999.

Street, R. A., Owen, S., Duckham, S. C., Boissard, C., and Hewitt, C. N.: Effect of habitat and age on variations in volatile organic compound (VOC) emissions from Quercus ilex and Pinus pinea, Atmos. Environ., 31, 89-100, 1997.

Tarvainen, V., Hakola, H., Hellén, H., Bäck, J., Hari, P., and Kulmala, M.: Temperature and light dependence of the VOC emissions of Scots pine, Atmos. Chem. Phys., 5, 989-998, doi:10.5194/acp-5-989-2005, 2005.

Tenhunen, J. D., Yocum, C. S., and Gates, D. M.: Development of a photosynthesis model with an emphasis on ecological applications. I. Theory, Oecologia, 26, 89-100, 1976.

Tingey, D. T., Manning, M., Grothaus, L. C., and Burns, W. F.: Influence of light and temperature on monoterpene emission rates from slash pine, Plant Physiol., 65, 797-801, 1980.

Tobolski, J. J. and Hanover, J. W.: Genetic variation in the monoterpenes of Scots pine, For. Sci., 17, 293-299, 1971.

van Roon, A., Parsons, J. R., and Govers, H. A. J.: Gas chromatographic determination of vapour pressure and related thermodynamic properties of monoterpenes and biogenically related compounds, J. Chromatogr. A, 955, 105-115, 2002.

Voirin, B., Brun, N., and Rayet, C.: Effects of daylength on the monoterpene composition of leaves of Mentha $\times$ piperita, Phytochemistry, 29, 749-755, 1990.

Vuorinen, T., Nerg, A.-M., Syrjälä, L., Peltonen, P., and Holopainen, J. K.: Epirrita autumnata induced VOC emission of silver birch differ from emission induced by leaf fungal pathogen, Arthropod-Plant Interact., 1, 159-165, 2007.

Wiberley, A. E., Linskey, A. R., Falbel, T. G., and Sharkey, T. D.: Development of the capacity for isoprene emission in kudzu, Plant Cell Environ., 28, 898-905, 2005.

Wilkinson, M. J., Monson, R. K., Trahan, N., Lee, S., Brown, E., Jackson, R. B., Polley, H. W., Fay, P. A., and Fall, R.: Leaf isoprene emission rate as a function of atmospheric $\mathrm{CO}_{2}$ concentration, Global Change Biol., 15, 1189-1200, 2009.

Winer, A. M., Fitz, D. R., and Miller, P. R.: Investigation of the role of natural hydrocarbons in photochemical smog formation in California, Contract No. AO-056-32, prepared for the California Air Resources Board, Statewide Air Pollution Research Center, Riverside, California, USA, 1983.

$\mathrm{Wu}$, J. and Baldwin, I. T.: Herbivory-induced signalling in plants: perception and action, Plant Cell Environ., 32, 1161-1174, 2009.

Young, P. J., Arneth, A., Schurgers, G., Zeng, G., and Pyle, J. A.: The $\mathrm{CO}_{2}$ inhibition of terrestrial isoprene emission significantly affects future ozone projections, Atmos. Chem. Phys., 9, 27932803, doi:10.5194/acp-9-2793-2009, 2009.

Zimmer, W., Brüggemann, N., Emeis, S., Giersch, C., Lehning, A., Steinbrecher, R., and Schnitzler, J. P.: Process-based modelling of isoprene emission by oak leaves, Plant Cell Environ., 23, 585595, 2000. 